Exploring playfulness in paediatric music therapy using an action research approach.

\title{
RACHEL ALISON AUSTIN
}

\section{An exegesis submitted to Victoria University of Wellington in partial fulfilment of requirements for the degree of Master of Music Therapy}

Te Kōki - New Zealand School of Music

Victoria University of Wellington

2020 


\section{Contents}

Abstract

ACKNOWLEDGEMENTS IV

TABLE OF FigURES $\quad$ V

INTRODUCTION

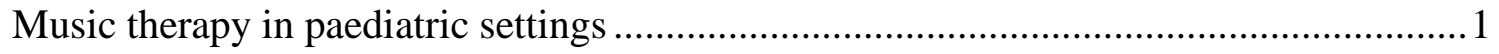

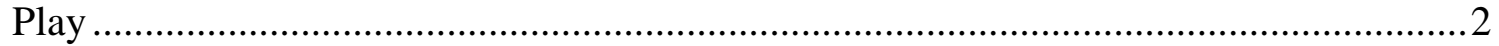

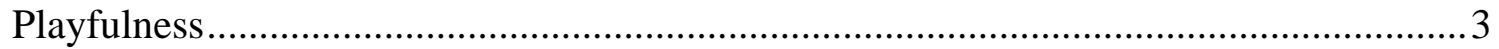

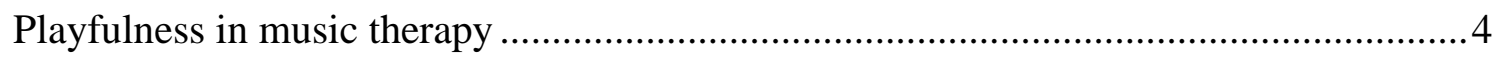

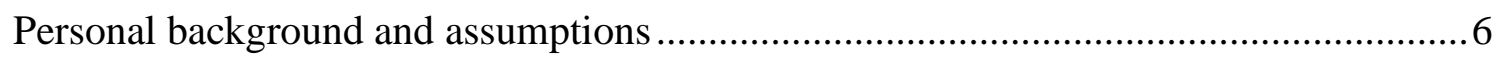

RESEARCH QUESTION

METHODOLOGY $\quad 7$

$\begin{array}{lr}\text { METHOD } & 8\end{array}$

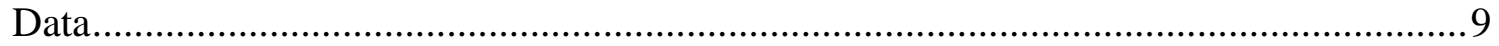

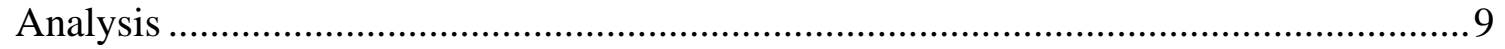

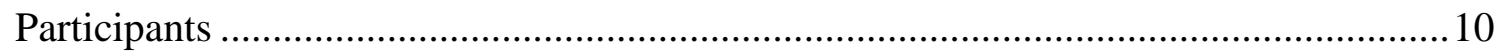

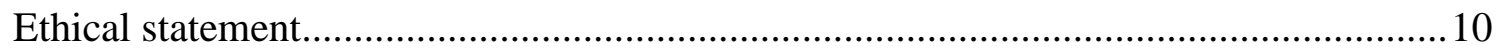

ACTION RESEARCH

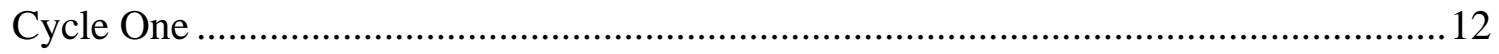

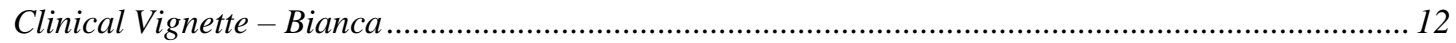

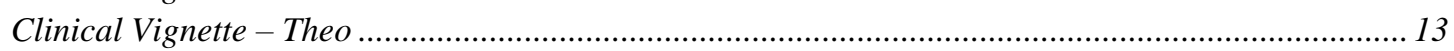

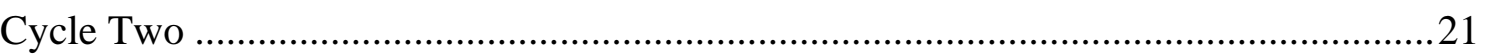

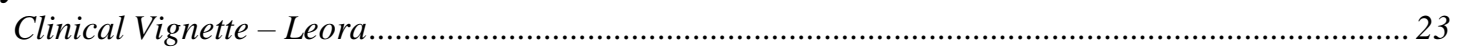

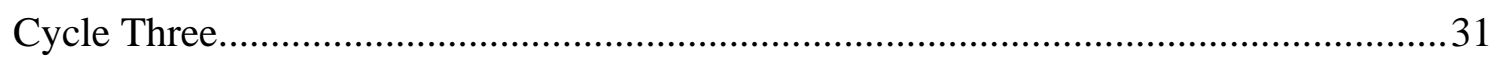

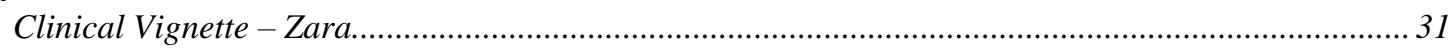

DISCUSSION

LIMITATIONS

CONCLUSION

REFERENCES

APPENDICES

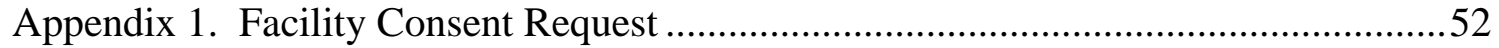

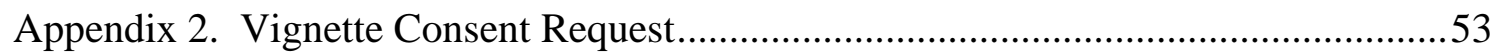

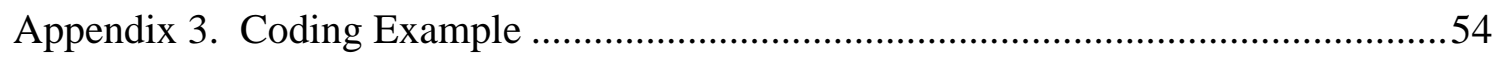

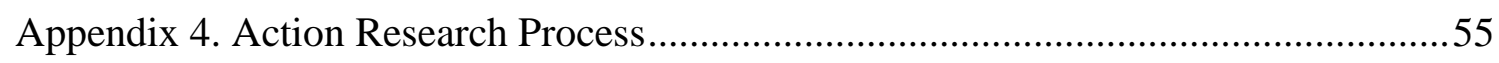




\begin{abstract}
Playfulness is a disposition which promotes adaptability across the lifespan. Attuned coplayfulness is a therapeutic tool requiring self-awareness of the disposition by the therapist. As a music therapy student working on a paediatric ward in a therapeutic play environment, the intersection of music therapy, therapeutic play and playfulness inspired this research. Specific research on playfulness in music therapy is limited. This research investigated playfulness in music therapy practice: how and when playfulness manifested in interpersonal interaction, both within and without music, to foster the therapeutic process.
\end{abstract}

Using an interpretivist, qualitative methodology and an action research approach, three cycles of action research were completed. Cycle one examined how playfulness was evidenced in my practice. Playfulness was evident when I was childlike, free from rules, the music therapy had elements of incongruence, I used humour or experienced joy. Playfulness was most evident with children up to five years of age. Cycle two explored playfulness in music therapy with children in middle childhood. Themes from this cycle included giving children time to warm up, using humour and primarily, collaboration. Cycle three explored the context for playfulness. Playfulness was most evident when music therapy occurred in the playroom or at bedside, without interruption. Playfulness was more evident with a supportive family member present and when there was some familiarity between music therapy student and patient. Confidence levels, health status and responses to the hospital environment impacted on playfulness for both patients and the music therapy student.

Playfulness was shown to be a marker of health and wellbeing for the music therapy student. Experiencing a lack of playfulness was a potential indicator of secondary traumatic stress and the need for increased self-care. Exhibiting a lack of playfulness was an appropriate clinical strategy which enabled affective state attunement with participants, supporting the intersubjective therapeutic process. This research raises the relevance of playfulness as a viable therapeutic marker in music therapy for children and adolescents, and as an indicator of wellbeing for music therapists. The findings are specific to this research setting and period and are not generalizable. 


\section{Acknowledgements}

Thank you to all the staff, families and children on the paediatric ward who worked with me during my placement and research. It was a privilege to work with you and spend time in your company.

A very special thanks to the wonderful hospital Play Specialist, who guided and supported me through the highs and lows of my time there and taught me so much.

Thank you to my Visiting Music Therapist for her mentoring and professional advice; for working through the challenges of practice with me and celebrating the successes.

I am sincerely grateful to Associate Professors Sarah Hoskyns and Daphne Rickson for their teaching, guidance, encouragement and inspiration. I learnt so much from their example and have benefited so much from their experience, knowledge and wisdom. A special thank you goes to Daphne for her expert supervision of this research.

I am deeply thankful to my music teachers Flora Edwards and Elaine Sharman. Their willingness to tutor me as an adult student enabled me to pursue music therapy, engage in this research and venture down new pathways.

Thank you to my student colleagues and friends Anna, Colette and Lucy who were my fellow travellers on the journey.

Thank you to my friends and faith family who encouraged me along the way, supported me in prayer and kept me grounded in my faith.

Thank you to my sisters and extended family, to my children Claire, Vaughan and Eilish, and especially my husband David, who endured this research alongside me and helped me through to the end. You all mean so much to me and I am forever grateful.

Thank you to God who inspired me and sustained me. 


\section{Table of Figures}

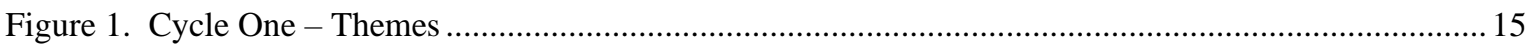

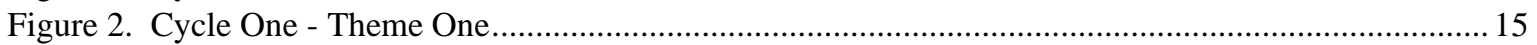

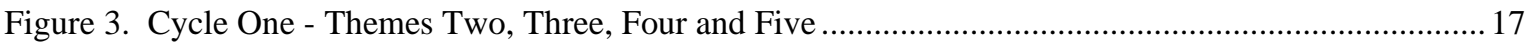

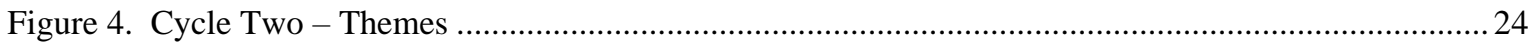

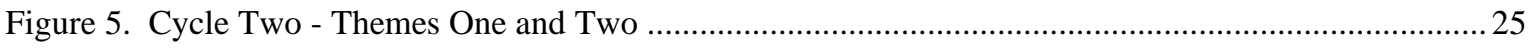

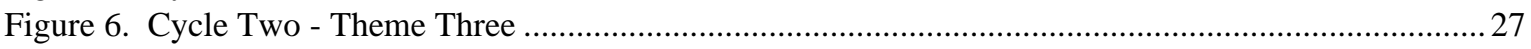

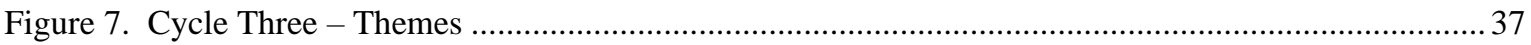




\section{Introduction}

\section{Music therapy in paediatric settings}

When a child attends hospital as a patient, the experience is broader than the illness or injury that caused their admission (Hannan, 2008). Treatments are often invasive, painful and determined by others. A child may face changes in appearance or function. A child may experience a loss of control; fear and confusion are common. They may experience separation from family and friends, while encountering countless hospital staff (Turry, 1999; Wolfe \& Waldon, 2009). With frequent or extended hospital admissions, a child may experience a disruption to their usual opportunities for learning (Howard \& McInnes, 2013; Neugebauer, 2013).

The use of music therapy with children in hospital is an effective way to help children cope with the many facets of the experience (Edwards \& Kennelly, 2016; Lorenzato, 2005). The music therapy approaches, methods and strategies used by therapists are varied and adapted to meet these multifaceted client needs (Hannan, 2008). Neugebauer (2013) described three broad music therapy methods that therapists use with children in hospital: use of improvised music, use of recreated music and receptive music therapy. Simply, the creation of new music and recreation of existing music are active processes for patients which create opportunities for children and their families to express thoughts and feelings, enhance coping and aid relaxation. Receptive music therapy involves a patient listening to music, where the patient is more passive.

Psychological care of children and their families is a key component of music therapy in hospital. Music therapy can help a child express their emotional state and thereby promote coping and wellbeing (Edwards \& Kennelly, 2011). Music therapy can help a child adapt to the hospital environment (Brooks \& O'Rourke, 2002). A randomized controlled study by Yinger (2016) identified live, active music therapy between music therapist, child and parents as the factor which significantly reduced children's distress during immunisations. Likewise, Sundar et al. (2016) determined that music therapy which used live music, instrument playing and singing with children and parents during immunization, reduced children's period of distress. In a meta-analysis by van der Heijden, Oliai Araghi, van Dijk, Jeekel, and Hunink (2015) music therapy interventions were found to have reduced children's post-operative pain, anxiety and distress. Another meta-analysis by Lee (2016) 
showed that music therapy could be considered an "effective complimentary approach for the relief of acute, procedural, cancer and chronic pain in the medical setting” (p. 471).

Music therapy is helpful in areas beyond pain management. Music therapy is a vehicle for building relationships between families and hospitalised children, when normal ways of interacting are often disrupted (Horvat \& O'Neill, 2008; Lorenzato, 2005; Tucquet \& Leung, 2014). Horvat and O'Neill (2008) used family centred musical activities which involved turn taking, opportunities for leading, following and initiative to facilitate positive parent-child interactions. Ayson (2007) found that paediatric music therapy, which included parents, provided emotional support and fostered normalisation for children.

Lorenzato (2005) further highlights the role of music therapy to provide positive stimulation in an environment where negative stimulation is prevalent. This positive stimulation can reduce anxiety levels and increase coping in hospitalised children (Karakul \& Bolisik, 2018; Tucquet \& Leung, 2014) and helps maintain typical play behaviour (Wolfe \& Waldon, 2009). Involvement in a 20-30 minute music therapy session of live music of patients' choice, enabled surgical oncology patients to experience greater levels of relaxation and reduced levels of anxiety (Yates \& Silverman, 2015). More recently, Yates, Beckmann, Voss, Anderson, and Silverman (2018) studied the experience of children who underwent bone marrow transplant. Children participated in instrument play and lessons, music for physical movement, music for relaxation, and musical books. Music therapy benefited these children by reducing the impact of isolation, negative mood and decreased activity, while normalizing their experience. Caregivers valued music therapy as it helped them and their child cope, promoting their mutual psychosocial wellbeing. Stegemann, Geretsegger, Phan Quoc, Riedl, and Smetana (2019), in their overview of music therapy and music-based interventions in pediatric health care, conclude that music therapy is a safe intervention that can relieve symptoms and improve a patient's quality of life.

\section{Play}

Across the decades, adults have emphasised the importance of play for children's biopsychosocial development, education, and recreation (Howard \& McInnes, 2013). Defining play is challenging. Eberle (2014) states that placing a quantitative definition on the myriad qualitative functions and effects of play results in restricting play and that static 
language cannot represent play's dynamism. Following extensive discourse on the many aspects of play which could feed into a definition, Eberle (2014) offers this: "Play is an ancient, voluntary, 'emergent' process driven by pleasure that yet strengthens our muscles, instructs our social skills, tempers and deepens our positive emotions, and enables a state of balance that leaves us poised to play some more" (p. 231). Academics across domains have espoused theories relating to the purposes and motivations of play in childhood. While the theories differ, they share the assumption that play is beneficial to children while also being a complex phenomenon which is difficult to measure (Fagen, 2010; Howard \& McInnes, 2013). Features of play include: a sense of security (Sayeed \& Guerin, 2000); freedom (Howard \& McInnes, 2013); movement, emotion and creativity (Fagen, 2010); a spiritual connection to the self, and to others or the universe (Harrison \& Robinson, 2017). The outcomes of play are extensive and include the development of flexibility, adaptability, resilience and problem solving; a sense of self and other; communication and relationships; self-regulation and self-esteem; and emotional expression (Hart, 2017; Howard \& McInnes, 2013; C. E. Schaefer \& Drewes, 2014).

Play belongs to health and the growing, healthy child plays (Winnicott, 2005). Duarte (2017) suggests that play restores internal equilibrium for a child after a traumatic event. In hospital, play bridges the gap between life outside hospital and life within it, creating a sense of normality (Ayson, 2007; Hubbuck, 2009). Play reduces anxiety, helps children and young people cope with their illness and treatment, provides an outlet for feelings and fosters family involvement ("Hospital Play Specialists Association of Aotearoa/New Zealand," 2019; Howard \& McInnes, 2013; Jones, 2018). Musical play involving practiced musical behaviours and known songs, can act as a transitional object for a child, helping them navigate between their internal self and the external environment, especially when that environment is unfamiliar or uncertain (Custodero, Calì, \& Diaz-Donoso, 2016; Winnicott, 2005). The literature outlined shows that both play and music therapy offer support for children in hospital and amelioration of their experience.

\section{Playfulness}

Playfulness, described as a state of mind, a disposition, attitude and approach (Alcock, 2016; Bennett, 2016; Guitard, Ferland, \& Dutil, 2005; Howard \& McInnes, 2013) typically occurs in a secure, stress-free environment (Bateson, 2015). It is an ingredient in play but is separate to the observable act of play (Howard \& McInnes, 2013). Playfulness brings 
evolutionary benefits to the human species by enabling us to be adaptable, flexible and inventive (Gordon, 2014). Playfulness is present in infancy and can develop into a feature of adult character (Akhtar et al., 2011). Liberman's (1977) physical, cognitive and social spontaneity, along with manifest joy and a sense of humour are foundational to the understanding of playfulness in young children. Spontaneity, freedom from rules, imagination, imitation and invention are the features of playfulness according to Tegano and Moran (2007). Playfulness tolerates unknown endings (Guitard et al., 2005).

Playfulness is also described as a mutual experience of light-hearted spontaneity, bold paradox and harmless pleasure with another person - "a source of joy for all the parties involved" (Akhtar et al., 2011, p. 77). This interpersonal aspect of playfulness is important. Alcock (2016) claims that there is a rhythm to playfulness which promotes attuned, intersubjective and collaborative interactions between adults and children. However, attuned play can only occur when the co-players read and respond appropriately to the cues of play. For an adult to be an effective co-player, they need both a clear awareness of the qualities of their own playfulness (Howard \& McInnes, 2013) and to fully enter playfulness with a child, while remaining conscious of the impact of their interactions (Tegano \& Moran, 2007). This duality - maintaining a 'bird's eye' view while being fully playful - means playfulness has positive potential in therapeutic work with children and adolescents (Hess \& Bundy, 2003; Trevarthen \& Panksepp, 2017). Most importantly, playfulness is a pivotal goal and indicator of positive health (Winnicott, 2005).

Playfulness is directly linked to creativity and innovation - tangible new behaviour or thought (P. Bateson, 2013). Similarly, Winnicott (2005) describes the importance of play and especially playful play, as the essential precursor of creativity. Both link creativity directly to the disposition of playfulness: Bateson (2013) emphasises creative outcomes, whereas Winnicott (2005) positions creativity as an internal impulse essential to the full experience of living, in which a person discovers their true self. While interesting, this interrelationship between playfulness and these two expressions of creativity is beyond the scope of this work.

\section{Playfulness in music therapy}

Specific references to playfulness in the music therapy literature are few. Oldfield (2006) frequently refers to playfulness in descriptions of her music therapy work, especially when 
improvising with children. While she highlights the importance of physical movement as a means of being playful, Oldfield does not elaborate on the scope of playfulness. Bradt et al. (2015) reported that adult cancer patients experienced playfulness when participating in interactive, creative music making. This playfulness connected them to their own internal coping resources. Similarly, O'Callaghan, Dun, Baron, and Barry (2013) associated playful and creative music therapy with increased normalcy and hope for children diagnosed with cancer.

The descriptive terms used for playfulness bear strong similarities to those used to describe improvisation in music therapy. As Bruscia (1987, p. 5) states, improvising in music therapy is "inventive, spontaneous, extemporaneous, resourceful, and it involves creating and playing simultaneously." Improvisation in music therapy also "unfolds in playful dialogues" and leads to "fuller participation in musical collaboration" (Trevarthen \& Panksepp, 2017, p. 47). Wigram (2004, p. 160) states that improvisation in music therapy "by its nature is a spontaneously creative and dynamic process where client and therapist are responding to each other, sometimes at an unconscious or intuitive level." He emphasises the importance of the therapist establishing an environment which promotes a participant's creative improvisation i.e. creative output and that playfulness is an improvisation method involving surprise and exaggeration. Note how Wigram, Bruscia, Panksepp and Trevarthen mention interpersonal connection during improvisation; partnership and collaboration are core components, as they are in playfulness (Alcock, 2016). Other common aspects outlined above include spontaneity, imitation and invention (Tegano \& Moran, 2007). The literature, therefore, leads me to assume that an attitude of playfulness accompanies music therapy improvisation.

There is also some cross over between playfulness and humour. A current review of humour in music therapy (Haire \& MacDonald, 2019) found that humour was an often assumed component of music therapy work. Haire and Oldfield (2009), when exploring humour in music therapy in paediatric psychiatric settings, found repetition, imitation, exaggeration and incongruity to be key features. Similarly, Amir (2005) identified components of musical humour which included exaggeration, incongruity and imitation. It is evident that playfulness, humour and improvisation have features in common. 


\section{Personal background and assumptions}

My interest in playfulness began prior to my music therapy training when I worked in Early Childhood education. Relationships with children in early education environments revolved around play. I also worked with groups of new parents and their infants, where I both modelled and observed playful infant-adult interactions. I learnt the value of a playful approach in building relationships. Reflecting on my interest in this area, I realised that I naturally relate to children and young people in a playful manner. As a music therapy student, practicing music therapy under a therapeutic play specialist, investigating playfulness in my music therapy practice seemed logical and presented an opportunity to explore the intersection of these disciplines. Play Specialists provide therapeutic, ageappropriate play experiences for patients and other children visiting the ward. I was interested to explore how playfulness and music therapy interacted appropriately, effectively and sustainably in the hospital setting. Therefore, this research investigated playfulness in music therapy practice: to explore how and when playfulness manifests in interpersonal interaction, both within and without music, in order to foster the therapeutic process. The intention was not to solve a problem through my research but to improve my practice by exploring what I did and why.

During this research I engaged in music therapy with patients and their families on a paediatric ward at a general hospital in New Zealand. I worked under the supervision of and in collaboration with the Hospital Play Specialist. I used a child centric, child development focused approach, as appropriate for this setting (Neugebauer, 2013) and drew on aspects of psychodynamic music therapy (Isenberg, 2015), especially Winnicott's (1971) psychotherapeutic stance on play (cited in Isenberg, 2015). 


\section{Research Question}

How is playfulness incorporated into music therapy practice in a paediatric setting?

\section{Methodology}

This research sat within the interpretivist approach using a natural setting as its context (Wheeler \& Bruscia, 2016). The research focused on my, the therapist's, perspective of music therapy sessions. This approach allowed my dual roles as music therapist and researcher to co-exist in conjunction with reflexive practices. As Wheeler and Bruscia (2016) state, reflexive practice can "lead to in-depth reflection and insight that effect change in one's own clinical practice" (p.32). Within this, relativity and subjectivity are inherent and any knowledge gained will be context specific. 


\section{Method}

I utilised an action research framework for this work. This was appropriate as action research enables research to be an active process, that exists and emerges in a real world context, where the desired outcome is empowerment and practical change (Stige \& Skewes McFerran, 2016). Kemmis, McTaggart, and Nixon (2014) state that the desired result of action research is to "feed and nurture self-reflection about our practices, our understandings of our practices, and the conditions under which we practise"(p. 70). This is most appropriate for a student music therapist as it provides scope to acknowledge my role as a co-player in the therapeutic space.

Action research has a clear beginning and set process. At the outset, the full scope and direction of the research could not be pre-determined. The potential to adjust the design as cycles progressed was important (Stige \& Skewes McFerran, 2016; Wheeler \& Bruscia, 2016). The cycles followed Lewin's (1948) five step action research process: Step one: identifying and defining the problem; two: fact finding; three: planning; four: implementation; five: evaluating outcomes and processes. These evaluations determined the beginning of the next cycle. While I did not set out with a specific 'problem,' I began with a question about how playfulness could be incorporated into my work in the hospital setting, and a desire to improve my practice in response to what I learnt. Wragg (1994, cited in Costello, 2003) described a kind of action research he called 'intuitive proactive'. Here, practitioners who believe they know what needs to be done, implement the intervention, and then evaluate the intervention. I similarly believed playfulness would be naturally incorporated in my work but was interested to discover how and when it was helpful.

This project involved three cycles of research. Each cycle consisted of five weeks of data gathering, followed by three weeks of data analysis, evaluation and planning. (See Appendix 4).

In the first cycle, I sought to identify the elements of playfulness I already engaged with in my practice. I anticipated that I would develop a construct that described my understanding of playfulness from the results of the first cycle. 


\section{Data}

This action research sought to understand the role of playfulness in my work. Therefore, I collected qualitative data in three forms: 1) my clinical music therapy notes;2) my reflective journal which documented my reflections on my practice; and, 3) a research journal. These sources kept the focus on my own work and met the ethical requirements of conducting research in a facility that both serves and protects the privacy of vulnerable people. The clinical notes were anonymised to exclude any personal details of patients or the facility. The research journal documented thinking, learning and reflecting relating to the research process, the development of my understanding of playfulness through each cycle of analysis and exploration of the relevant literature. These three data sources, which grew out of my daily music therapy experiences, provided opportunities for the reflexive process (Bergold \& Thomas, 2012 ; Bruscia, 2013) and provided thick, descriptive data, essential for quality qualitative research (Wheeler \& Bruscia, 2016). The three sources of data were complementary and accumulative, but all were generated by me and not diverse enough for me to claim I captured different dimensions of the same phenomenon, i.e. that I engaged in triangulation.

\section{Analysis}

Prior to analysis all data were anonymised. For each research cycle I analysed data using inductive analysis (Wheeler \& Bruscia, 2016) and identified codes and themes using the qualitative research software, NVivo. NVivo allowed me to interact with, compare and consolidate data and subsequent codes, progressing through Williams and Moser's (2019) open, axial and selective coding stages. Qualitative software provided an "easier capture of the coding and construction of meaning" (Williams \& Moser, 2019, p. 48). Each of the three data sources were analysed this way and the results integrated into the resulting themes. The resulting themes sparked questions and exploration of further literature.

At the outset, I assumed that the research may indicate playfulness to be a positive tool in my practice. However, I was open to it showing the opposite. I needed to ensure that I documented my work honestly, in suitable detail, and maintained an open attitude to the results of the thematic analysis. 


\section{Participants}

Over the course of this research, I worked with children aged birth to fifteen years of age, who were patients, siblings or visitors of patients admitted to a general paediatric ward. I also interacted with adult family members and staff. These interactions are evident in my data. Whilst I was the primary participant in the research, it was difficult to examine my playfulness in a vacuum, as music therapy is not a solitary practice. If patients, family members or staff are mentioned as co-players in music therapy, they remain anonymous through use of pseudonyms. My music therapy practice remained the focus of the research.

\section{Ethical statement}

The VUW Human Ethics Committee has given generic approval to NZSM Master of Music Therapy Programme ethical template for student research in NZSM 526 undertaken as observational studies, theoretical or case study research or action research (ref: \#22131, 2015). This study has been judged to be low risk and, consequently, was not separately reviewed by another Human Ethics Committees.

I adhered to the Music Therapy New Zealand Standards of Practice and Code of Ethics. In my role as a student therapist and researcher, my music therapy participants were children, young people and their families, admitted to or visiting the children's ward. They were a vulnerable population due to their young age and compromised health status. I worked with many people from different cultural backgrounds. Sometimes there were challenges with communication and differences in cultural practices. I was careful to not assume commonality in people's perceptions of playfulness. I did my best to work with and respect the languages, backgrounds and cultures of those I met. I always gave people the option of participating in music therapy. In recording my work, I ensured my documentation preserved the anonymity and confidentiality of the organisation and the participants. I recorded the age of the children I worked with however, as this impacted the analysis of my practice.

I received consent from the facility to carry out my research (See Appendix 1). I ensured participants entered an informed consent process and understood their rights to participate or withdraw from the research. I kept all data secure and disposed of it at the end of the research period. 
I have included four vignettes in this exegesis. Each vignette documents four individual music therapy sessions with four different children. Informed consent to include descriptions of my work with these children was gained from their parent and/or guardian after their discharge from hospital. The head of the facility gave consent for these retrospective requests. Again, pseudonyms have been used to protect the children's privacy.

Respecting Te Tiriti o Waitangi and the principles of practice, participation and protection within it, I discussed my research with the hospital Play Specialist, who identifies as Te Atiawa $^{1}$. She did not identify any issues related with my research. I continued to discuss these principles and aspects of te ao Maori ${ }^{2}$ with her over the course of my research and sought her input, especially in my role as practitioner.

\footnotetext{
${ }^{1}$ Te Atiawa is the name of a Maori tribal group in New Zealand.

${ }^{2}$ Te ao Maori refers to the Maori world, Maori institutions and cultural resources (Kingi et al., 2018).
} 


\title{
Action Research
}

\author{
Cycle One
}

Which elements of playfulness are evident in my music therapy practice?

\section{Clinical Vignette - Bianca}

(From Clinical Music Therapy Notes - March 11)

Bianca was a two year old who had been in hospital for a few days with abdominal pain. She had been cautious of the playroom and had not ventured in much. She was gradually becoming more adventurous and had started to come in for short periods. I noticed her coming out of her room and walking towards the playroom with her caregiver. Playing the ukulele, I started to sing (to the tune of Oma Rapeti), 'Hello Bianca, hello Bianca, won't you come on in? She looked at me, seemingly surprised, smiled and came into the playroom. She went directly to the keyboard and pushed the demo button; it started to play pre-programmed music. At that moment, her nurse arrived; it was time for Bianca to have some medicine via nasal gastric tube, which Bianca didn't like very much. I offered to support Bianca and the nurse during this procedure and went to her room with my ukulele and a frame drum. Bianca sat on the side of the bed, facing me. The nurse stood behind her on the other side of the bed and began administering the medicine.

Bianca's hands were bandaged to prevent her from removing her nasal gastric tube. I offered her the drum. With encouragement she started to hit the drum with her hands. I improvised songs as she played, playing ukulele as I sang. Her caregiver held the drum for her. I sang an invitation to play the drum with her feet, then with her knee, with her elbow, with her head, with her other foot. Her caregiver moved the drum and held it in the relevant places for her. She played the drum with each body part and smiled as she did so. We played a game where the music started and then suddenly stopped. I then sang about the drum being in different places - up, down, over to one side, then over to the other side - and her caregiver moved the drum into each position keeping it within Bianca's reach. I made my vocal pitch reflect the change in position as I sang. Bianca looked delighted as she responded to the sudden unpredictability of the play and the vocal representation of the drum position. She continued to play enthusiastically.

I had been making up lyrics for a while so decided to continue with the silliness of the game and sang scat 'bibbidy, bibbidy, biddidy ba, diddity, diddity, diddity da....' I started 
each phrase with an exaggerated inhalation, raised torso and eyebrows; I wiggled my head as I sang. I provided space for Bianca to play after each phrase, continuing with ukulele only, strumming the rhythm of my scat. She beat the drum energetically, using big movements, with two hands, her feet moving with her hands, swinging back and forth. She was animated and engaged in the music and the game. The nurse then finished administering the medicine: Bianca had hardly noticed the nurse nor the medication. I turned the ukulele over and used it as a drum, drumming the back of it. She looked at me and shook her head. I said, "This way?" I turned it on its head, held it between my knees and played the base of it like a drum. She shook her head but smiled. Again, "This way?" I turned it so I played the tip of the neck. She shook her head, involved in the game. She motioned for me to turn it over. "This way?" I drummed on the strings. She shook her head. I started to strum; she started to drum, seemingly satisfied with the return to music. She was then collected for an $x$-ray and the session finished.

Clinical Vignette - Theo

(From Clinical Music Therapy Notes - March 12)

Theo was a 20 month old, admitted for burns to his stomach and arm. I worked with Theo in the treatment room as he underwent a long and sometimes unpleasant dressing change. A little later the same morning, Theo and his family came to the playroom. I wasn't sure how he would respond to me after his dressing change and gave him time to acclimatise to the room. I wanted to foster a positive experience of the play space and of music in hospital. Theo came over to his mother sitting on the couch. I was sitting at the other end of the couch. Without saying anything, I held a drum out to him and hit it softly; his mother hit it too. He was watching, interested. I offered Theo and his mother a beater, I had one too. He hit the drum then wanted my beater. I gave it to him and found an extra one for myself. I hit the drum and looked at him expectantly, keeping my beater slightly raised above the drum. Mum hit the drum. Theo hit the drum again. Then he hit the frame of the drum on the side - bang, bang, bang, bang. I hit the side too. He hit it again, so did I. I matched his tempo and sang "It sounds different on the side” ... hit, hit, hit.... "it sounds different on the side." He drummed the side some more, then shifted to the top of the drum. I drummed the top too and sang "it sounds different on the top" and we hit the top. He was now using the beaters continuously with both hands. He moved over to the table; he drummed the table. I drummed the table too and sang "it sounds different on 
the table...it sounds different on the table." He took a step towards the chair and started beating the chair, I followed again and sang, "it sounds different on the chair." He came back to the drum; we played the drum... "it sounds different on the drum." This game continued with Theo playing the table and the chair again before coming back to the drum, playing the top and the sides again. I followed his lead and sang about each action each time. He sustained a regular beat as he moved around each item.

He then turned his attention to a shaker. I picked up my guitar, continued with the same energy and tempo and sang, to the tune 'Twist and shout' by The Beatles ${ }^{3}$, “Well, shake it up baby now, (shake it up baby), shake your shaker, (shake your shaker), come on, come on, come on, come on baby now, (come on baby) shake your shaker, (shake your shaker); Well you shake so fine, (shake so fine) and you shake so good (shake so good) come on and shake it, shake it, shake it now; like I knew you would, (like I knew you would)....Ahh, ahh, ahh, ahh...." As I sang and played, Theo danced his body side to side, moved around the room, shaking his shaker periodically.

In this first cycle I sought to identify the elements of playfulness I already engaged with in my practice. Was playfulness present? Did it present in the ways the literature suggested? The literature suggested that playfulness was spontaneous, joyful, humorous, (Lieberman, 1977), inventive, imaginative and free from rules (Tegano \& Moran, 2007). These established features of playfulness were helpful as I began to look at my data.

The data for this cycle came from my work with twenty five children aged up to five years, twelve children aged six to twelve years and one adolescent. I discovered that playfulness was evident in my work when I was childlike, free from rules, when the music therapy had an element of incongruence, when I used humour or was joyful.

${ }^{3}$ Berns, B., \& Medley, P., (1961). Atlantic Records. 
Figure 1. Cycle One - Themes

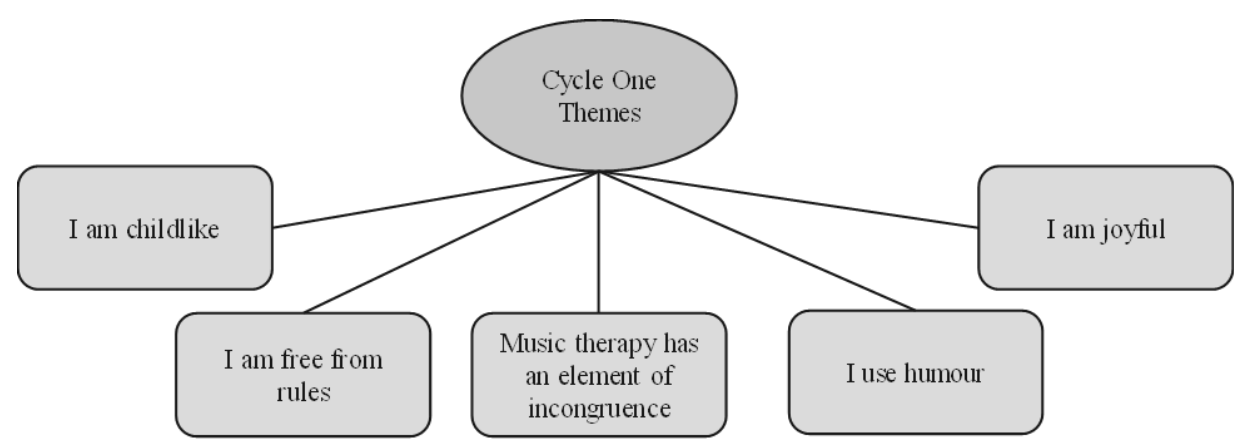

Figure 2. Cycle One - Theme One

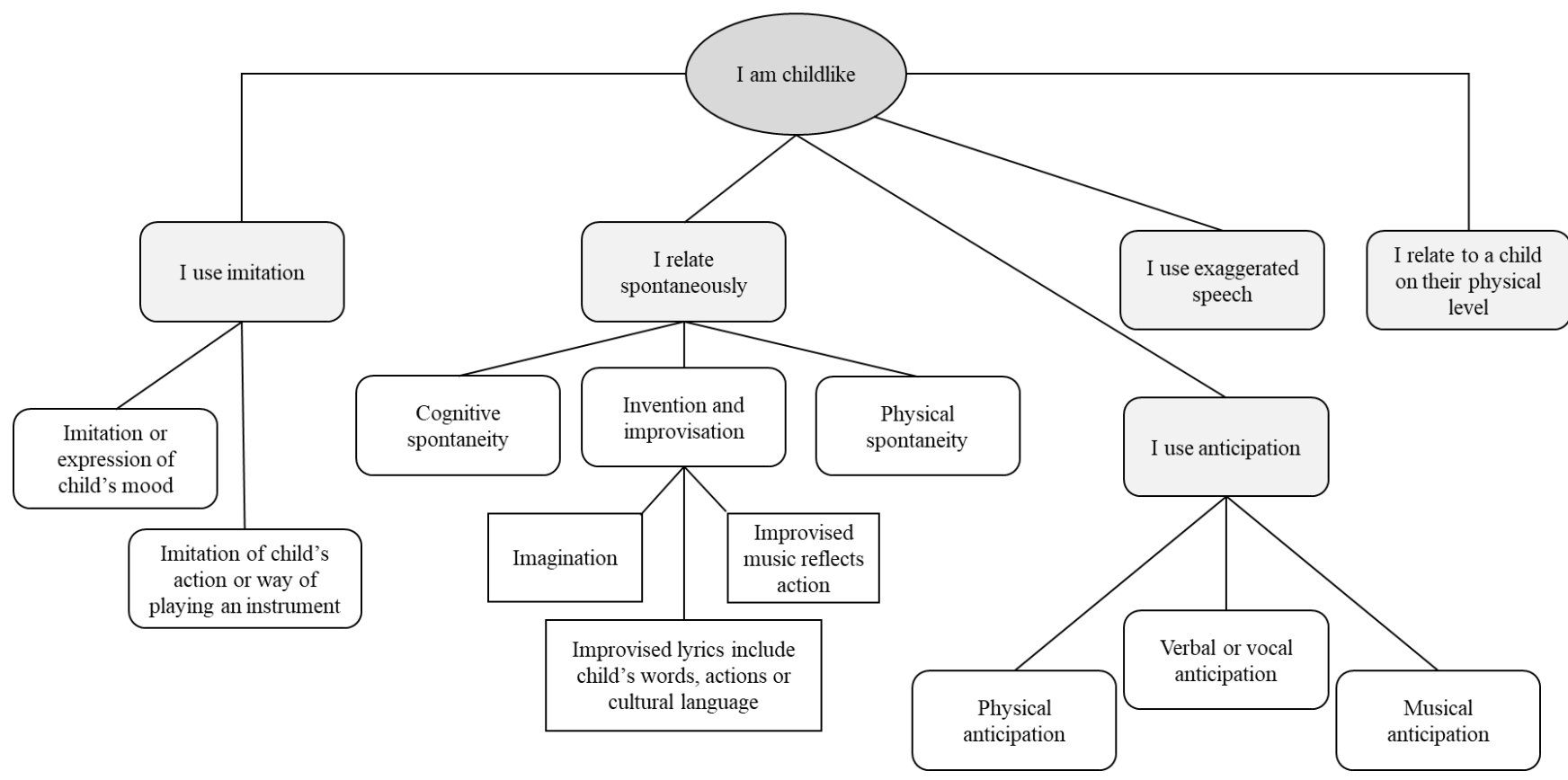

Being childlike was the strongest theme, capturing multiple ways of being with and interacting with children. Relating spontaneously was important in this theme and included invention, improvisation and imitation in language, action or music. The use of anticipation, matching the child's physical level and the use of exaggerated speech or nonspeech sounds were the other components of being childlike. The following example describes physical spontaneity within a session, with a four year old at the electric keyboard:

He used the palm of his hand, fingers outstretched, positioned at right angles to the keys, to press down a whole series of notes at once. I followed him and did the same. He put his whole forearm down, making sure notes were sounding from his 
elbow to his fingertips while looking up at me; I put my forearm down too, sounding as many notes I could and looking at him, smiling. "Can you move your arm along like a caterpillar?" I asked, waving my forearm, hand and fingers along the keys. He moved his arm along the keys too. We both 'caterpillared' the keys in different places, switching places and enjoying the sounds. The timing didn't matter so much but I tried to do my movements in between his. Suddenly I stopped 'caterpillaring' and played with my elbow. He followed, playing with his elbow too. We were having lots of fun.

(Clinical music therapy notes, March 14.)

Relating spontaneously frequently involved being inventive and improvising. I would spontaneously create song lyrics that reflected a child's actions or repeated a child's words. I learnt that I did this a lot. On reflection, I realised that incorporating happenings in the moment into an improvised song came easily to me. Using music elements rather than lyrics to reflect my actions, a child's actions or to communicate playfulness, did occur but much less often.

Often, various aspects of being childlike occurred concurrently. For example, the use of anticipation using instruments and the use of exaggerated speech with a two year old in the excerpt below.

I strummed the guitar rapidly then stopped suddenly. He looked at me. I did it again, changing chords and saying an extended "Goooooo and STOP!" He smiled. I kept playing and stopping. He started to laugh, although he could not vocalise much and made no sound. His eyes were bright. He had a large open mouth, smiling, tilting his head back.

(Clinical music therapy notes, March 20.) 
Figure 3. Cycle One - Themes Two, Three, Four and Five

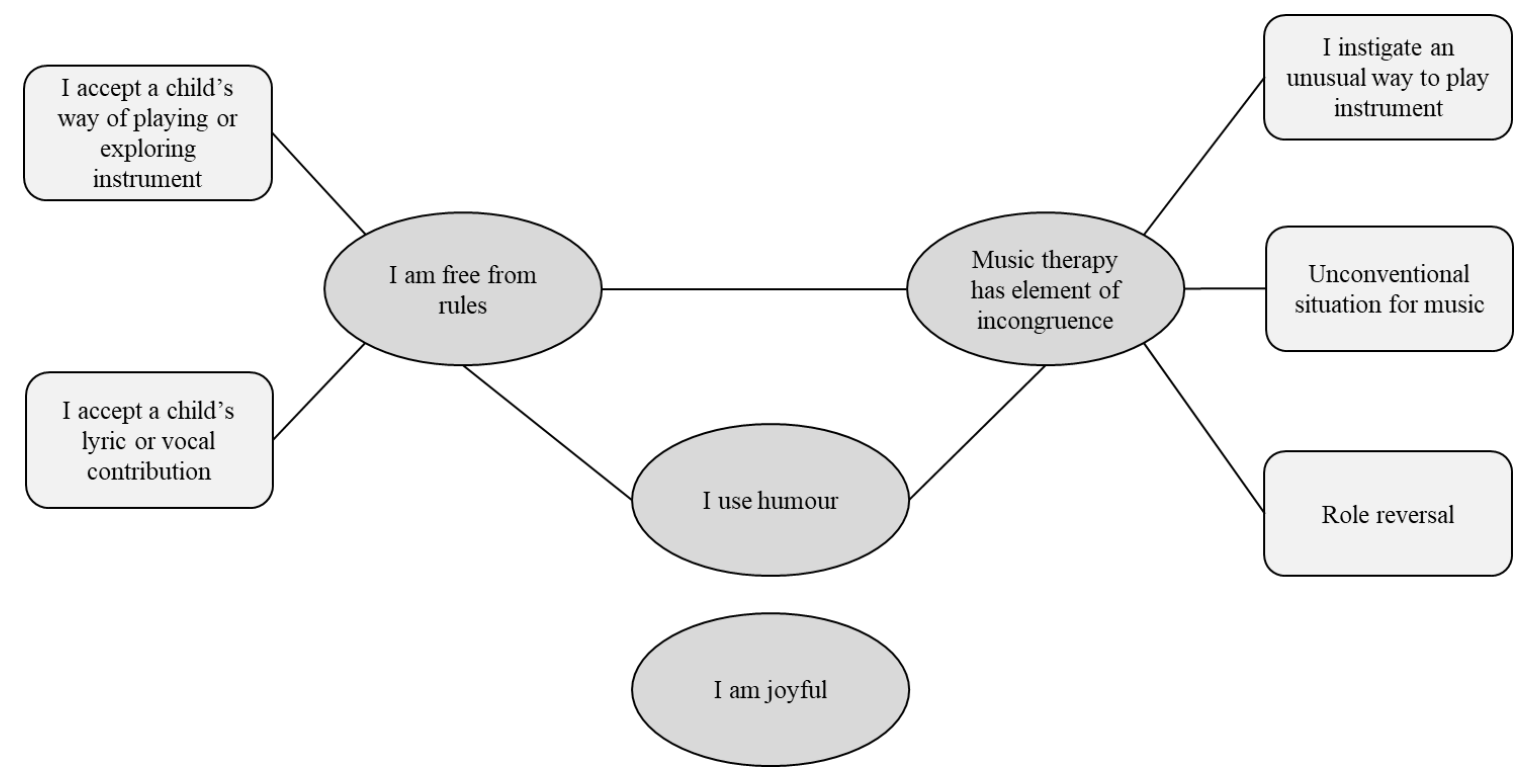

The next two themes, 'I am free from rules' and 'My music therapy involves elements of incongruence,' are similar as they both involve the unexpected. However, I identified a subtle difference. If a person is free from rules, the implication is that they are not following the conventions of behaviour or practice. When I was free from rules, I accepted children's musical contributions irrespective of how they played an instrument; I did not enforce a 'right' way of playing. If a child played the guitar strings with beaters, I did too. Likewise, I accepted children's contributions to song lyrics as we created or altered songs together. For example, I purposefully created an opportunity for children to 'break the rules' of polite conversation when extending a song about increasingly disgusting things to eat, like toenail soup and dandruff pie. I noticed their expressions of cautious delight as they added "snotty chips" and "poopie bird" to the song.

If something is incongruent, it is not suitable or does not fit with something else; it is ambiguous, logically impossible or inappropriate. In the context of the hospital, music is generally incongruent. This theme related to the situations I took music into; the way I instigated the playing of instruments and the role I took as music therapist. This example, with a two year old in the playroom, illustrates the incongruence of improvised song creation to accompany a medical procedure:

[I had already been working with Grace, making up songs about her block play when a doctor arrived to see her.] After an initial greeting, the Senior House 
Surgeon asked, "Can I listen to your lungs?" Grace gave a definite "No!" The doctor told her grandmother and me that he would respect her wishes. Thinking on my feet, I said to Grace, "Shall we make up a song for the doctor while he listens?" "Yes!" she said, nodding. Playing the ukulele, I improvised: "Lift up your pyjama top, the doctor will listen to your lungs." She let the doctor put his stethoscope on her back. I quietly sang "He listens.... (pause); he listens ......(pause). As he finished, I sang "Well done!"

(Clinical music therapy notes, March 27.)

Similarly, incongruence was evident when music therapy was used in the medical treatment room. For instance, playing live music during the application of a cast for a fractured arm is not a typical occurrence for a patient. For a seven year old child with Autism Spectrum Disorder who became distressed with the procedure, singing about the nurse winding the cotton wool "round and round and round and round and round and round and round" and then the nurse singing too, relaxed the child and gave him a point of focus. My playfulness created a situation where medical staff were singing and playful as they worked - incongruence. Role reversal was also evident in other aspects of my work, especially when I encouraged children to step out of the role of patient, into the role of teacher, where I became the learner.

The use of humour was the fourth theme. Humour was very situation dependent and by nature often involved elements of incongruence and surprise (Murdock \& Ganim, 1993, cited in P. P. G. Bateson, 2013). When I used humour my tone of voice was generally light and jesting; sometimes humour involved word play. It was frequently spontaneous. Sometimes it created shared experiences of manifest joy.

Four year old Bella made lots of chicken noises as we sang about Old MacDonald having a chicken on his farm. In the pause between verses I said, "Shall we sing the whole song like a chicken?" She nodded and smiled. I launched into tuneful chicken clucks. Bella immediately joined in with delight, as did her mother. We sang the whole song with 'bock, bock, bocks' and 'bup, bup, bups,' trying not to laugh as we sang.

(Clinical music therapy notes, March 20.)

The final theme was 'I am joyful.' This theme involved emotional delight experienced in 
music making and interaction during music therapy. Data coded to this theme often described being caught up in the music - where I brought a joyful tone to the singing, energy to the playing and the music facilitated a joyous response in the child. Working with a three year old in the playroom who took a sudden interest in a ukulele:

I started singing 'Whole lotta shakin' goin' on, ' (by Jerry Lee Lewis $\left.{ }^{4}\right)$, with a smile on my face and in my voice and playing ukulele with a rock'n'roll feel. "Come along Elijah, can you play the ukulele? Come along Elijah, can you play the ukulele, I ain't fakin,' can you play the ukulele." As I sang, Elijah danced, moving his hips from side to side, strumming his ukulele. His face lit up; he was smiling a big smile.

(Clinical music therapy notes, March 12.)

And, with another three year old outside the treatment room prior to a procedure:

I introduced myself to Benjamin and his family outside the treatment room.

Benjamin told me his favourite song was 'Move it, move it's (from the film Madagascar $\left.{ }^{6}\right)$. I sang it right there, in the moment, with a groove in my body and a finger click. He wasn't expecting that! He smiled and joined in.

(Clinical music therapy notes, March 11.)

The aim of this cycle of research was to find tangible evidence of playfulness in my practice. I learnt that playfulness was evident when I was childlike, free from rules, when the music therapy had an element of incongruence, when I used humour or was joyful. While each theme is distinct, they have an interconnectedness due to the complexity of social interaction in playfulness. The varied features of non-verbal and verbal communication, the nuances of timing relating to spontaneity, anticipation, joy and humour in the moment plus the multidimensionality of musical communication, led to many sessions of work being categorised into multiple nodes and consequently relating to more than one theme.

While it is possible to look at individual themes and the nodes which are categorised under them, it is possibly more helpful to review the wider pattern of playfulness that these

\footnotetext{
${ }^{4}$ Dave "Curlee" Williams, (1955).

${ }^{5}$ Erick Morillo \& Mark Quashie, (1994)

${ }^{6}$ DreamWorks Pictures
} 
themes create. Burgoon and Bacue (2003) state that when examining the meaning of nonverbal communication cues, it is pertinent to examine them as "constellations of cues" (p.187) within both context and intent. When examining playfulness as a constellation of actions across my data, I discovered that playfulness was more evident in my practice with children under five years of age. On reflection I found it very easy to be playful with younger children; I could draw on many years' experience working with this age group and I was adept at putting off my adult self to relate to young children in a playful way that was easily understood by them. I noticed that being playful seemed to build rapport and trust with young children.

I found it more difficult to be playful with children in middle childhood, aged five to twelve. When I was playful with older children, it occurred in 'role reversal', 'freedom from rules' and when I taught them a new skill, like playing the ukulele. I wondered if a sense of rapport and trust was required before older children would consider engaging in mutual play or playfulness. I also realised I was concerned with what older children thought about what I offered them. I was often concerned that what I offered was not 'cool' enough. It is possible my demeanour communicated my lack of confidence and my lack of confidence meant I quickly accepted any dismissal of music therapy. I needed to enhance my music therapy practice with children in middle childhood. If being childlike i.e. taking on the characteristics of young children's play and playfulness, worked in practice with children zero to five, surely the same applied to older children. I needed to better understand play in middle childhood and then develop strategies and techniques to help me relate to and utilise playfulness with this age group. Consequently, investigating playfulness with children in middle childhood was the focus of cycle two. 


\section{Cycle Two}

\section{How do I incorporate playfulness into my practice with children in middle childhood?}

The first task of Cycle Two was to increase my understanding of play and playfulness in middle childhood by examining the literature. Sourcing literature on this topic was difficult; an issue corroborated by Howard, Miles, Rees-Davies, and Bertenshaw (2017) in the documentation of their small scale investigation into children's perspectives on play. Their study showed that children in middle childhood were emotionally invested in play irrespective of the type of play. Freedom and choice were key features of play alongside compromise and negotiation. Typical types of play included: electronic play activities, outdoor and indoor games, pretend play and play with toys. Fromberg and Bergen (2015) and Arnett (2012) state that play in middle childhood demonstrates children's increasing cognitive, social, emotional and physical capabilities. Play includes practice play that increases a child's physical or cognitive skills, co-operative pretence, games with negotiated rules and roles and, construction or artistic play involving building and design. Social play becomes more complex, more co-operative and collaborative (Zembar, 2009). Adults can take an active role in facilitating play in middle childhood by: providing play resources that can allow for adaptation, imagination and creativity; engaging in play interaction by providing real choices and build trust by appreciating the play process, without judging outcomes; appreciating the multiple ways children display a sense of playfulness; and, supporting gender equity in play options (Fromberg \& Bergen, 2015).

Psychosocially, children in middle childhood are developing their self-concept: their ideas about their personality, abilities, gender and ethnicity solidify. They engage in greater social comparison and are therefore prone to greater self-criticism and self-consciousness (Berger, 2014). Children become more adept at regulating their emotions and can hide their true emotions from others. This contrasts with the greater emotional impulsivity of early childhood. Reasons for friendship ties also change: in early childhood, common interest in an activity or toy is enough to foster friendship, whereas in middle childhood, companionship in play is dependent on trust (Arnett, 2012).

A Maori perspective on development (Ritchie, 1994, cited in Drewery, 2004) provided a clearer focus regarding the importance and significance of building rapport and trust, of 
collaboration and negotiation, of caring for the psychosocial-spiritual, whole person in the New Zealand context. Of particular relevance were aroha (acceptance), manaakitanga (care for others), rangatiratanga (self-determination), kotahitanga (consensus) and whanaungatanga (relationship through shared experiences creating a sense of belonging).

It is worth mentioning musical play specifically. This too is identifiable in the player's degree of choice and control, pleasure and intrinsic motivation. In middle childhood, musical play is often constrained by space, materials, context and adult's perceptions. “'Everyday' forms of musical activity happen in the places children inhabit when not engaged in organized activity" (Marsh \& Young, 2015, p. 2). Marsh and Young continue, describing how musical play for children in middle childhood is impacted by the formal education system, with its emphasis on standardised musical skill development. Spontaneous musical play tends to be pushed into child-only contexts, like the playground, and involves singing and clapping games of oral tradition; chants and songs associated with skipping, ball games, counting out; singing and dance routines related to popular culture; and, sports chants. Musical play in middle childhood has a strong emphasis on peer relationships through teaching and creating variations in music, lyrics or movement (Marsh \& Young, 2015).

Considering the literature, I developed a set of strategies and techniques to add to my existing music therapy 'tool kit.' (See Table 1 below.) My increased understanding, along with the security of added structure and ideas, boosted my confidence: hopefully, opportunities for playfulness would ensue. 
Table 1. Cycle Two: Strategies and techniques

\begin{tabular}{|c|c|}
\hline $\begin{array}{l}\text { Relax. } \\
\text { Build rapport. } \\
\text { Enjoy the process. }\end{array}$ & $\begin{array}{l}\text { Follow the child's interests in the playroom or at } \\
\text { bedside, interact without the pressure to engage in } \\
\text { any task. }\end{array}$ \\
\hline $\begin{array}{l}\text { Add a selection of accessible and relatable music } \\
\text { therapy resources to my existing resources, which } \\
\text { would provide choice, embrace technology, provide } \\
\text { cognitive challenge, foster creativity and promote } \\
\text { collaboration. }\end{array}$ & $\begin{array}{l}\text { Use technology } \\
-\quad \text { Music composition software. } \\
-\quad \text { Smart phone application consisting of looped } \\
\text { beats in various genres. } \\
-\quad \text { Access to pre-recorded music via smart phone } \\
\text { application. } \\
\text { Promote creativity } \\
-\quad \text { Song writing frameworks and picture cards for } \\
\quad \text { lyric prompts. } \\
\text { Provide opportunities for practice play: learning or } \\
\text { playing instruments } \\
-\quad \text { Provide multiple ukuleles for teaching and } \\
\text { learning. } \\
\text { Provide resources for making traditional Maori poi }{ }^{7} \\
\text { and porotiti }{ }^{8} \text {. }\end{array}$ \\
\hline $\begin{array}{l}\text { Create music games with rules or use music to } \\
\text { accompany stories. }\end{array}$ & $\begin{array}{l}\text { Music games } \\
-\quad \text { Rhythm games with plastic cups } \\
\text { - } \quad \text { Simon says with instruments or body } \\
\text { percussion } \\
-\quad \text { Who stole the cookie from the cookie jar? } \\
-\quad \text { Hot/cold game } \\
-\quad \text { Freeze frame }- \text { musical statues }\end{array}$ \\
\hline
\end{tabular}

\section{Clinical Vignette - Leora}

(From Clinical Music Therapy Notes - June 12)

Leora was an eleven year old who had spent a few weeks in hospital with a hip condition. Cognitive stimulation and sustained interaction were important for her. One afternoon in the playroom I suggested we write a song. Leora was not sure about this, so I said that I understood it might seem a weird thing to do, if you haven't done it before. She nodded in response. I suggested that we write a song together and she warmed to that a little. Wanting to remove any remaining task focused pressure, I suggested I write the song and she help me. This was an acceptable plan. I fetched the picture cards I had for song writing: "How about this, we'll use these cards. You pull one out like a lucky dip and whatever you pull out, I have to put that word into the lyrics." She smiled and took the cards; she really liked this idea. The first card she pulled out was 'leaf.' I quickly wrote down 'Our love is like a leaf.' She took some delight in how this was going to

\footnotetext{
${ }^{7}$ Poi is a light ball on a string of varying length, swung or twirled rhythmically to accompany music.

${ }^{8}$ Porotiti is a disk with two holes through which a string is threaded, that hums when it spins (maoridictionary.co.nz)
} 
work. Leora drew another card and the process continued. I suggested a lyric, asked her opinion. I then slowly invited her to make more suggestions. I guided the process but it really became a collaboration. Once happy with the lyrics, Leora guided the development of the melody and feel of the song, choosing a looped hip hop beat from the beat application on my phone. We recorded the song with the beat accompaniment. The process involved much hilarity and she became much more confident in offering her ideas. She seemed very pleased and proud of the result. We performed the song for the Play Specialist.

\section{The Break-Up Song}

(Underlined words were the cards Leora drew out of the pack. Leora's lyric contributions are in standard text, mine are in italics)

Our love is like a leaf but you drive me nuts

When you put on your shoes, you don't show any love

Our love is like a vase, with no flowers inside

This is why you drive me nuts; I'm saying goodbye---

Just get on your horse and ride away

The goat's gonna catch you, before the sun melts you

I'm getting on my jet, 'cause I stole your money - shame on you

You can go camping, while I'm flying to Hawaii--- Peace Out!

In this second cycle I sought to answer the question: How can I incorporate playfulness into my practice with children in middle childhood? First, I developed a greater understanding of play and development in middle childhood and better equipped myself for practice with this age group. Second, analysis of data from work with nineteen children showed that playful moments occurred when there was time to warm up, during collaboration and in humour.

Figure 4. Cycle Two - Themes

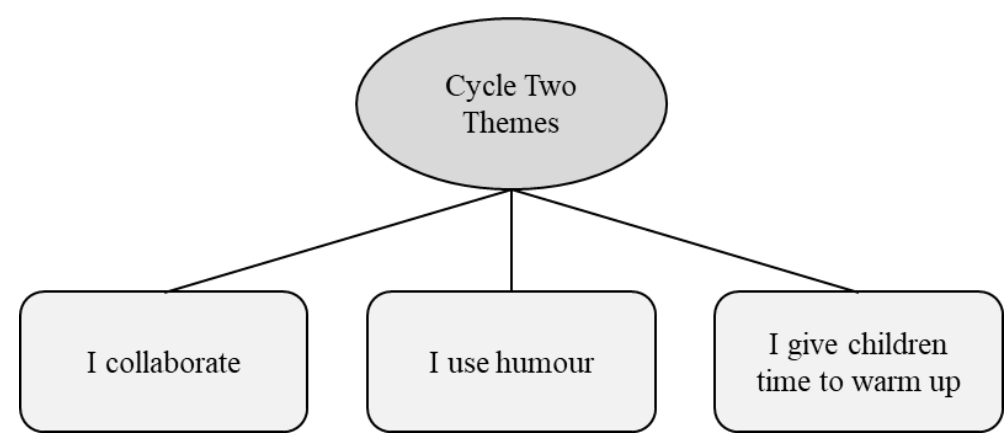


Figure 5. Cycle Two - Themes One and Two

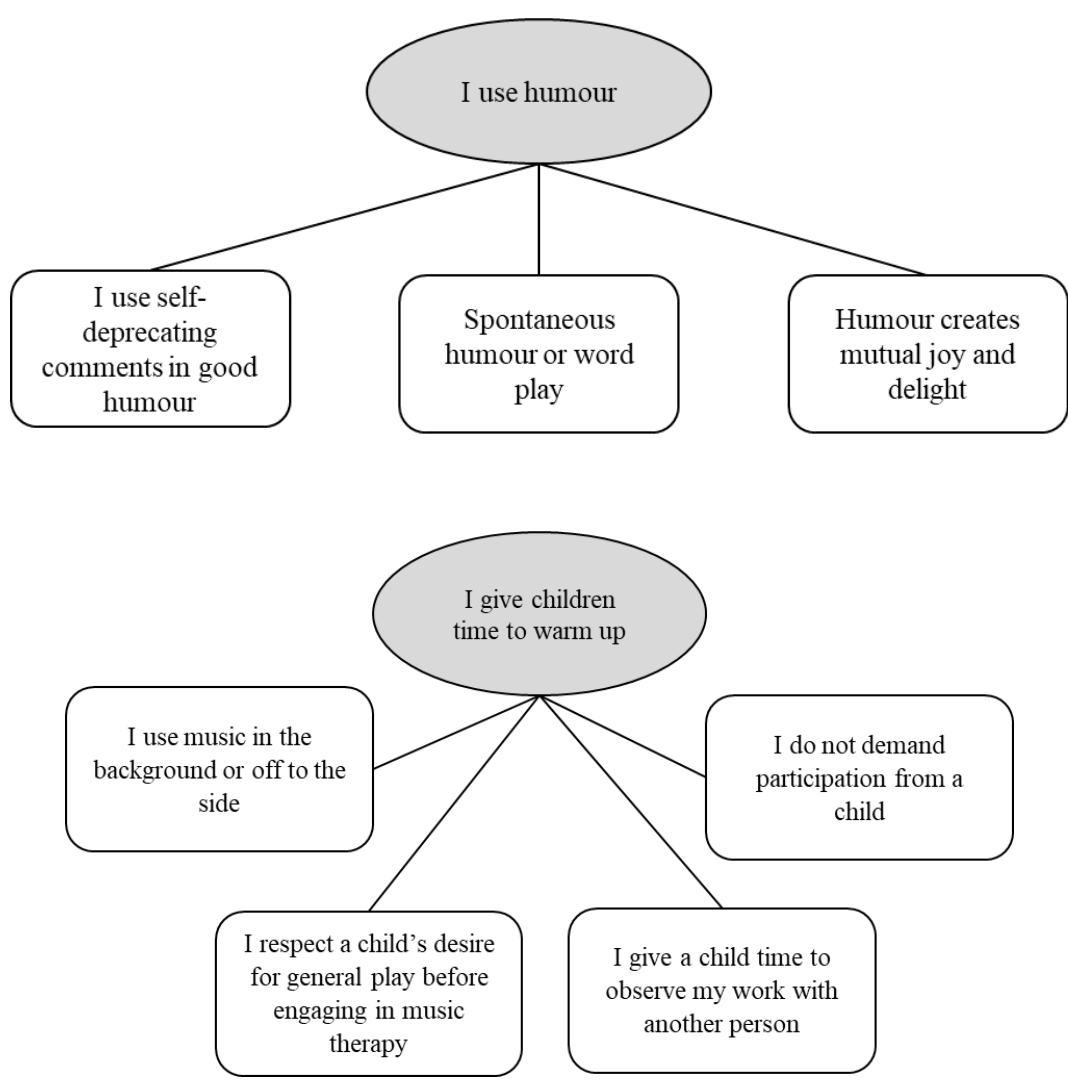

The first theme was time to warm up. This was about consciously removing any pressure on myself or a child to promptly begin music therapy; it was about aroha, manaakitanga and rangatiratanga (Ritchie, 1994, cited in Drewery, 2004). Using live music in the background, giving a child time to observe my work with others, not demanding their participation and respecting their need to follow their own agenda were important. This example highlights giving a child time to observe and not demanding their participation.

I was working in the playroom with Gemma (4) when Zoe (6) came in. She went and stood at the playdough table, which was positioned in front of a large mirror. Gemma and I had been making music together - me with guitar, Gemma with a drum. Zoe avoided looking at me apart from the occasional glance in my direction. As I worked with Gemma, Zoe's father offered Zoe a maraca. She took this, shaking it occasionally. Gemma and I continued in our music as I sang 'Shake, rattle and roll' (recorded by Bill Haley and his Comets ${ }^{9}$ ). I adapted the

\footnotetext{
${ }^{9}$ Written by Charles E. Calhoun a.k.a. Jesse Stone (1954)
} 
lyrics to accommodate drum and maraca and both girls played their instruments Zoe sporadically. Gemma was called away from the room but I continued, singing different songs. When I got to the 'la la la' section of a chorus, Zoe joined in. She had kept her back to me the whole time but was constantly watching me in the mirror.

(Clinical music therapy notes, April 30.)

Respecting a child's agenda is evident in this case with a ten year old:

I provided the materials she needed to make and decorate a card for her mother.

As I sat beside her and she worked on the card, she started humming Ka Waiata ${ }^{10}$.

I listened. When she finished, I commented, "That's a lovely song." I asked if I

could hum it with her and play the song on guitar. She agreed. As I did this, softly, she sang the words.

(Clinical music therapy notes, May 8.)

The next theme and least prominent, was the use of humour. I deliberately used humour as an equaliser, to lessen my role as expert and become more of an equal player in the relationship. Humour also featured in improvised song lyrics. As in Cycle One, humour remained 'in the moment.'

${ }^{10} \mathrm{Ka}$ Waiata is the title of Maori hymn. 
Figure 6. Cycle Two - Theme Three

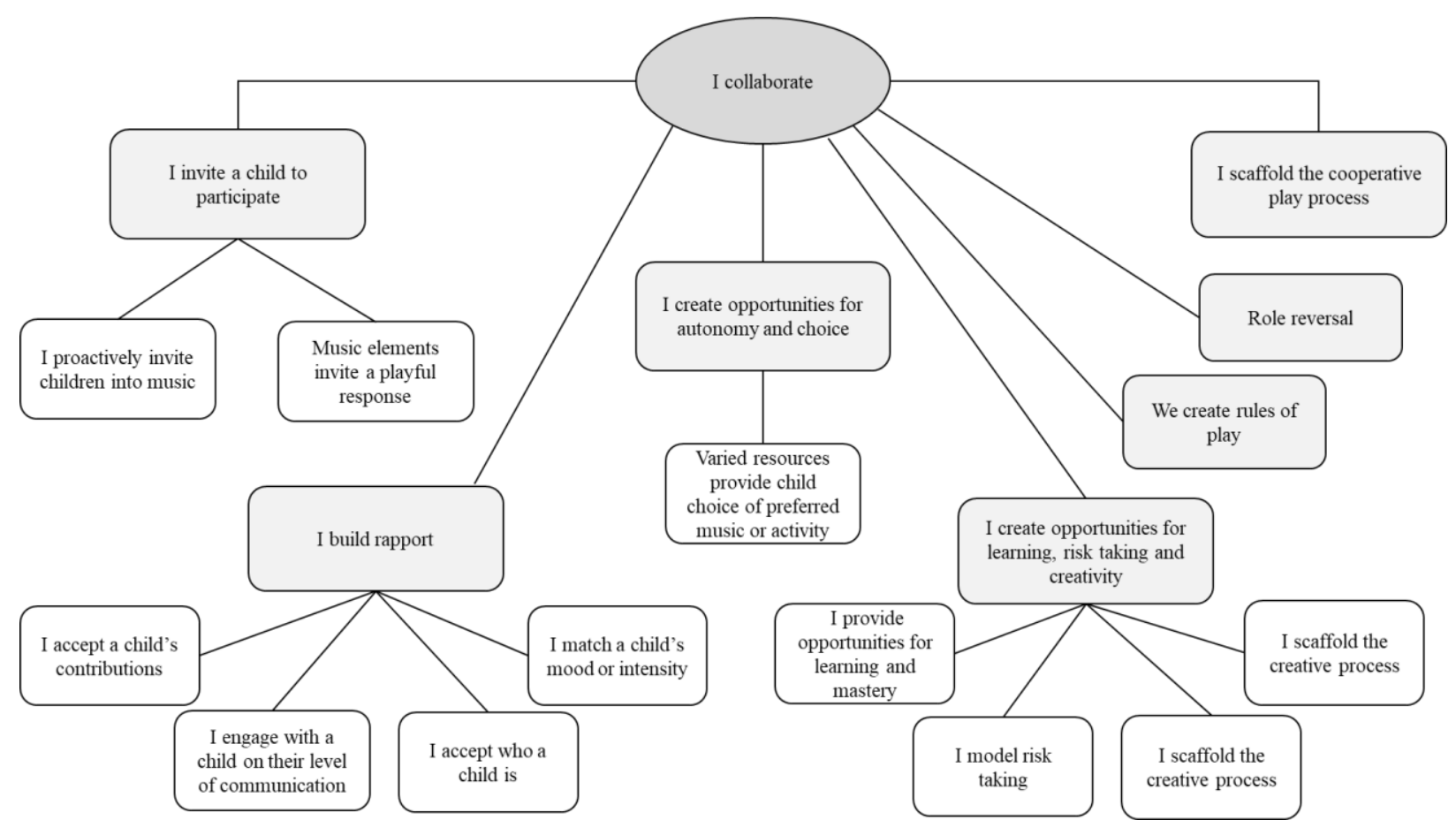

The most encompassing theme was collaboration, a key aspect of being 'childlike' in middle childhood and an anticipated gateway to playful interactions with this age group. While indicated in the literature, evidence for collaboration and its components was gathered through examination of data. Acts of collaboration included inviting children to participate; building rapport; creating opportunities for autonomy and choice; creating opportunities for learning, risk taking and creativity; creating rules of play; role reversal; and, scaffolding the cooperative play process. These were all proactive initiatives on my part. An invitation to participate in music therapy was either verbal or musical. Building rapport was primarily about accepting who a child was and how they presented, communicating on their level or matching their mood or intensity. Availability of a range of instruments, song charts, pre-recorded music and creative music materials provided scope for choice, while opportunities for autonomy were frequently created by offering open ended suggestions or following a child's lead. I created opportunities for risk taking, learning and creativity through invitations to learn or renew instrument playing skills, through song writing and by modelling or encouraging trial, error and general participation in improvisation. Scaffolding the cooperative play process meant modelling and guiding 
the collaborative process for children who came to play with fewer interpersonal resources. The following data describes some of these features:

Amy (8) chose a hip hop beat (on a smart phone application) for us to play instruments to. She experimented fitting shakes on the maraca and hits on the drum into the spaces in the rhythmic pattern. She chose another beat and we decided to change instruments. We each tried different rhythmic fragments, fitting our playing around each other within the pre-recorded beat. We had times when we settled into a complimentary rhythmic pattern together. The tricky part was knowing when to stop as the beat was in a continual loop. I commented on this challenge in a light-hearted way. We agreed on a count down so we could stop playing at the same time. Communicating with head nods so we knew when to begin our count down, we counted down together and stopped with an accented beat $-X !$

(Clinical music therapy notes, May 8.)

In this excerpt from my practice journal, I reflect on a session with a reserved twelve year old who was a sibling of a long term patient.

I feel I am getting more confident approaching older children. I felt I had a good level of success with Julia, with both the guitar and the cup song. She wanted to learn to play my guitar. I taught her some simple chords and she played them a lot, practicing until her fingers were too sore. We then worked on the cup song together for a long time. The cup song created a positive environment for mutual learning, mutual trial and error and laughter. I was able talk about how I wasn't an expert, especially when I added the song to the cup rhythm. Ifelt this was helpful as it kept me in the position of learner. I was possibly more animated than her but she had presented as very quiet earlier in the afternoon. As we played with the cups, she smiled; she gave a small laugh at times. She initiated adding extra complexity to the game, suggesting we swap cups at the end of each rhythmic pattern. She also initiated another cup game, arranging the cups in a vertical pyramid and then testing how quickly she could stack them all up. We used the stopwatch on my phone to time our efforts - I timed her; she timed me. We also timed her sibling. As our cup play progressed it felt that we were equal 
collaborators in it - she would make suggestions about what we should do - how many cups to arrange and how. (Reflective practice journal, week of May 27.)

The examples above and Leora's vignette illustrate the general increase in my confidence and use of the devised strategies which led to moments of playfulness with children in middle childhood. Not all collaborations felt overtly playful of course. Engaging in playfulness was dependant on my assessment of how a child presented and their medical needs. On some occasions, however, I continued to notice a difference between how I was playful with children in early childhood and how I was playful with older children. I was able to be with older children in collaborative 'work' or 'play' but moving into 'playful collaboration' was more challenging; I wondered why. A music therapy mentor observed that although I was providing opportunities for choice and autonomy i.e. attempting to work collaboratively, I was not offering 'my side' of the negotiation as an equal participant. There was a difference between, "Shall we do this?" a less certain proposition, and "Let's do this," the question of an equal participant.

I continued to read about play and social-cooperative skills in children. Hayward, Raine, and Hendry (2019) wrote about the development of young children's negotiation skills in collaborative play. Of note was the ability of a child to negotiate their place in the play and to assess the success of a bid to influence a game. Fromberg and Bergen (2015, p. 32) concurred: "How to enter into play successfully is a negotiation skill and it requires practice and the opportunity to be with peers." As I read this, I realised that in my own middle childhood collaborative play was a challenge. My ideas were seldom taken up - or I was not confident enough to offer them - and I tagged along with what the leading children at school proposed, if I felt they let me. I often felt on the outside of my peer group and insecure of my place. I did not have similarly aged siblings at home and I engaged in a lot of solitary play there. I was not an expert negotiator. I suddenly saw that my past was impacting on how I entered into collaborations with children in middle childhood. This new self-awareness enabled me to understand the genesis of feelings about my work. This reflexive process, vital in music therapy practice (Bruscia, 2013), empowered me to reconnect with that part of my history but also establish some boundaries around it.

While my playfulness was under examination, the importance of a reciprocating partner in playfulness was beginning to surface. I could be playful but as Youell (2008, p. 122) 
emphasised, playfulness is a "two-person phenomenon" that takes time to foster within the parent-child relationship. Was playfulness in one or two sessions of music therapy with an unfamiliar playfellow automatically more difficult? Was playfulness compromised by illness or stress? Was it challenged by other factors? This led to the area of investigation for Cycle Three: How does context impact on playfulness? 


\section{Cycle Three}

\section{How does context impact on playfulness in paediatric music therapy?}

\section{Clinical Vignette - Zara}

(From Clinical Music Therapy Notes - August 21)

Zara was a thirteen year old who was experiencing neurological anomalies, causing problems with memory and involuntary movement. She was very anxious about an impending MRI scan and her family was highly distressed about her potential diagnosis. In consultation with Zara and her mother, we decided to use music for fun and relaxation at the bedside. Our initial musical encounter involved playing percussion instruments to pre-recorded KPop ${ }^{11}$, Zara's preferred music. After a tentative start on the bongos, she said that this was the first time she had done anything like this but she really liked it. I suggested we just have a 'jam' together and make up our music - I reassured her that there was "no wrong" in this type of music making. She relaxed some more. I joked that the only "wrong" would be if she, "Decided to throw the drum out the window!" "Or smash up the guitar!" she said. "Yes, that would be wrong!" I replied in a light-hearted tone. I asked how she would like the music to sound? I demonstrated the difference between major and minor chords, singing an improvised song about the feel of each chord, playing the matching chords on my guitar: Major - "I'm so happy, I've just bought some new jeans and I'm having ice cream for dinner; " minor - "My cat's run away and it's cloudy outside." She chose a mixture. I started to play. Zara played bongos again, following me, while I also modified my playing to support her. She became more confident in her playing as our music progressed, becoming more deliberate in her beat placement but also changing how she played. At one point she played with only her fingertips. I reduced my volume to pianissimo in response. She went back to playing with full open palms. I increased my volume to match. I could see she was preparing to play a louder beat, raising her hand higher. I matched her stronger downward motion with a minor chord, reinforcing the downward energy in the music. Part way through, I added an improvised vocalisation. We had some very synchronised moments in music and played for about 3 minutes. (This was not the end of the session but captures the essence of it.) The next day Zara decided to come to the playroom for music. She knew exactly what she wanted to do: we were going to improvise like yesterday. We sat on the couch and started

\footnotetext{
${ }^{11}$ Korean Pop Music
} 
our session on bongos and guitar; she wanted a "low" mood for the music. "Minor, like this?" (I played a minor chord.) "Yes" she said. I suggested she start. I picked up on her tempo and we were quickly in sync. After a while I added a vocalised melody. We kept playing together until the music came to a natural close. I asked her if she would like to add some words to the music. She immediately said she wanted to write a lullaby and out came the first line. The rest of the song just flowed out of her; it was all written in about a minute. I mentioned making up a tune. She started to sing, I followed. We worked through some of the finer points of the melody, clarifying some intervals. We sang the song through a few times to cement all aspects and settle on accompanying chords. She then said that she wanted to gift the song to me to use with children on the ward. Feeling moved, I suggested in return that we record the song and gift it to her family. Her sister used her phone to record Zara singing the song. I played the accompaniment and sang quietly to support her, allowing her voice to be prominent. This was a significant moment as the family had not yet had a diagnosis and were preparing for bad news.

During Cycle Three, I drew on the same data sources as I had for cycles one and two clinical notes, reflective practice and research journals - but I viewed the data through a different lens. I was exploring the context for playfulness within the hospital environment: where did the playful moments occur, and what was happening when they did not? This cycle of work coincided with a long period of significant challenge on the ward. The ward was consistently full, with many children requiring intensive medical monitoring and care. Alongside this, staff were caring for multiple long-stay patients with complex needs, including trauma, requiring inter-agency interventions which brought into focus wider systemic issues. As a music therapy student, I felt the effects of this and was immensely challenged by some of the patients' personal situations. I was also affected by a period of illness. I was increasingly conscious of reduced playfulness on my part. I was also aware of the situational appropriateness of being playful, reflected in part in Zara's vignette. My reflective practice journal became more central as a data source for understanding the context for playfulness: Was I feeling playful in this environment and if not, why not? Excerpts from my reflective practice journal illustrate the difficulty of this five week period. 
- I am trying not to show my distress about Patient A's homelessness (Reflective practice journal, week of July 29).

- I have a sense of hopelessness about Patient B; feel I should be helping; I'm frustrated at interruptions to music therapy work (Reflective practice journal, week of July 15).

- Feel I need to keep offering music therapy to Patient B but it seems pointless, feeling rejected. Feeling frustrated and angry at the system; unsure of my role (Reflective practice journal, week of July 22).

- I am struggling with frequent rejection by families /patients; struggling with inconsistencies in my role; struggling with many very sick children and limited opportunities for music therapy (Reflective practice journal, week of August 5).

- I am beginning to notice how picking up other people's non-verbal cues and their verbal responses impacts on my work and how I feel about myself. This affects what I feel I can offer. Asking permission to do music therapy and being rejected takes a toll (Reflective journal, week of July 22).

- Struggling with observing suboptimal parent-child interactions; feeling tense and angry (Reflective practice journal, week of July 15; week of July 22).

- This week I have been sick. It was a real struggle for me to engage with people; playfulness felt a long way away and just too hard. I am beginning to notice the lack of playfulness in myself as I have been unwell for over a month now. I also notice that in challenging circumstances, where I am not sure of my role or how I will be received, playfulness is kept at bay or at least feels as though it lacks authenticity - it is forced, even if I know it is appropriate for a patient. I am conscious of my diminished facial expressions now that I am sick. I have noticed myself consciously smile at patients when working with them and that this suddenly makes a difference to them (Reflective practice journal, week of July 22).

As I first explored the data, the more superficial aspects of context felt very distant: I was overly conscious, almost overwhelmed, by the psychological impact of this period. My perceived lack of playfulness weighed heavily on me and it felt important to understand this. Analysis showed that lack of playfulness was associated with my ill health, low 
confidence and low mood, as described above. Patients' pain, medication, treatment, their psychological state; familial distress; staff workload and stress also contributed.

Further, the following excerpt illustrates the inappropriateness of playfulness during patient and familial distress:

I used music therapy to support a fifteen month old child as they underwent the insertion of a nasal gastric tube. This was a difficult procedure requiring multiple attempts. This was very distressing for Shannon and her mother. Afterwards, as Shannon's mother cuddled and comforted her on the bed, I played guitar gently, then sang a modern lullaby. As I played, mother cried. I sang the song through a couple more times and finished just humming the tune. I left them both then, as Shannon was going to sleep and I wanted to give her mother some quiet time to continue her recovery.

(Clinical music therapy notes, July 16.)

After working through the data in this way, I realised I was very stuck within a negative perspective and that I had neglected to look for evidence of playfulness in the face of the contextual challenges. I revisited the data, categorising it using the codes and themes for playfulness from cycles one and two. I found that playfulness was still present, though not in as many ways.

Primarily, I was playful as I proactively invited children into music therapy, accepted and validated children's ways of playing instruments and promoted their role in the play. I continued to provide opportunities for learning, risk taking and creativity and resources continued to provide opportunities for autonomy and choice. I built rapport by accepting children's contributions and giving children time to warm up. There was less humour, less incongruence and fewer joyous moments during this period. However, there were numerous examples of meaningful shared music making, some of which were playful. The extract below highlights these themes. It also illustrates my growing awareness of some of my non-verbal behaviour. This first example occurred during the first week of cycle three. I had not yet felt the full impact of this challenging period but was becoming more aware of my level of playfulness in my work. Here I am working with a fifteen year 
old. We had worked together during a previous admission and were familiar with each other. She was learning ukulele for the first time and we were writing a song together. She was not very confident. I modelled the song writing process, which was also new to her. I provided opportunities for choice and learning and accepted her level of contribution. The excerpt describes part of our session:

We played our ukuleles together and I sang our new song. I checked that she was okay with the melody I had chosen, which she was. "You made the song fit with the ukulele!" she said in a surprised tone. We played the song through a few times. She became more confident with her chord changes and would look up to me as she played the instrument. I was suddenly aware of my neutral or possibly serious (concentrating) facial expression. In that split second, I made a conscious decision to smile back my approval and encouragement. She smiled in response, a big wide smile. It was if she could trust she was doing something right. She was so pleased.

(Clinical music therapy notes, July 10.)

In contrast, at the end of cycle three I felt the full effects of this difficult period. The aspects of playfulness identified in this cycle were still evident, but playfulness required all my effort. The patient was a three year old boy confined to his bed space and very bored.

Isaac chose the black drum and two beaters and started playing with a steady beat. I joined in with guitar, matching his energy and singing "What a way to start the day..."' I followed his lead as he changed instruments and I improvised song lyrics to reflect his actions. Choosing two claves, he tapped them on the instrument tray or together. I improvised: "Happy sticks tap, tap, tap... Happy sticks tap up, up, up; Happy sticks tap down, down, down... Where shall the sticks tap next? Over there?" (pointing to one side). "Over there?" (pointing to the other side). He pointed in the direction he wanted. We continued together. Suddenly, the toddler in the opposite bed came over and Isaac gave her a set of bells. She had very bandaged hands but managed to hold the bells between the two. She shook the bells up and down. I improvised a song about bells and they both continued to play. In the next moment, a very young, sleeping baby was wheeled into the room in a hospital cot - a new admission. I was very conscious of 
the noise of our music making and brought the session to a quick close.

(Clinical music therapy notes, July 23.)

Following the second round of analysis, my perspective brightened. I reviewed playfulness in the data for a third time and looked for the supposedly more superficial aspects of context. I identified the physical location of playfulness, who was present, whether the session was interrupted or uninterrupted and noted familiarity between participants. I learned that playfulness was more likely to occur a) in the playroom or at bedside (which were treatment-free zones), b) with a supportive parent or guardian present, c) when music therapy was uninterrupted and/or d) when participants were more familiar with each other.

Cycle Three analysis was complex and messy, requiring many revisions and reorganisations of codes and categories. Eventually I summarised my coding under two headings: 'Patient context' and 'music therapy student context.' Playfulness required two reciprocating partners (Youell, 2008) and understanding the impact of context on playfulness for each partner was key. 'Patient context' and 'music therapy student context' shared themes of 'confidence' and the 'impact of the hospital environment.' These, plus the third theme of 'health' and the associations between them, are displayed in Figure 7. 
Figure 7. Cycle Three - Themes

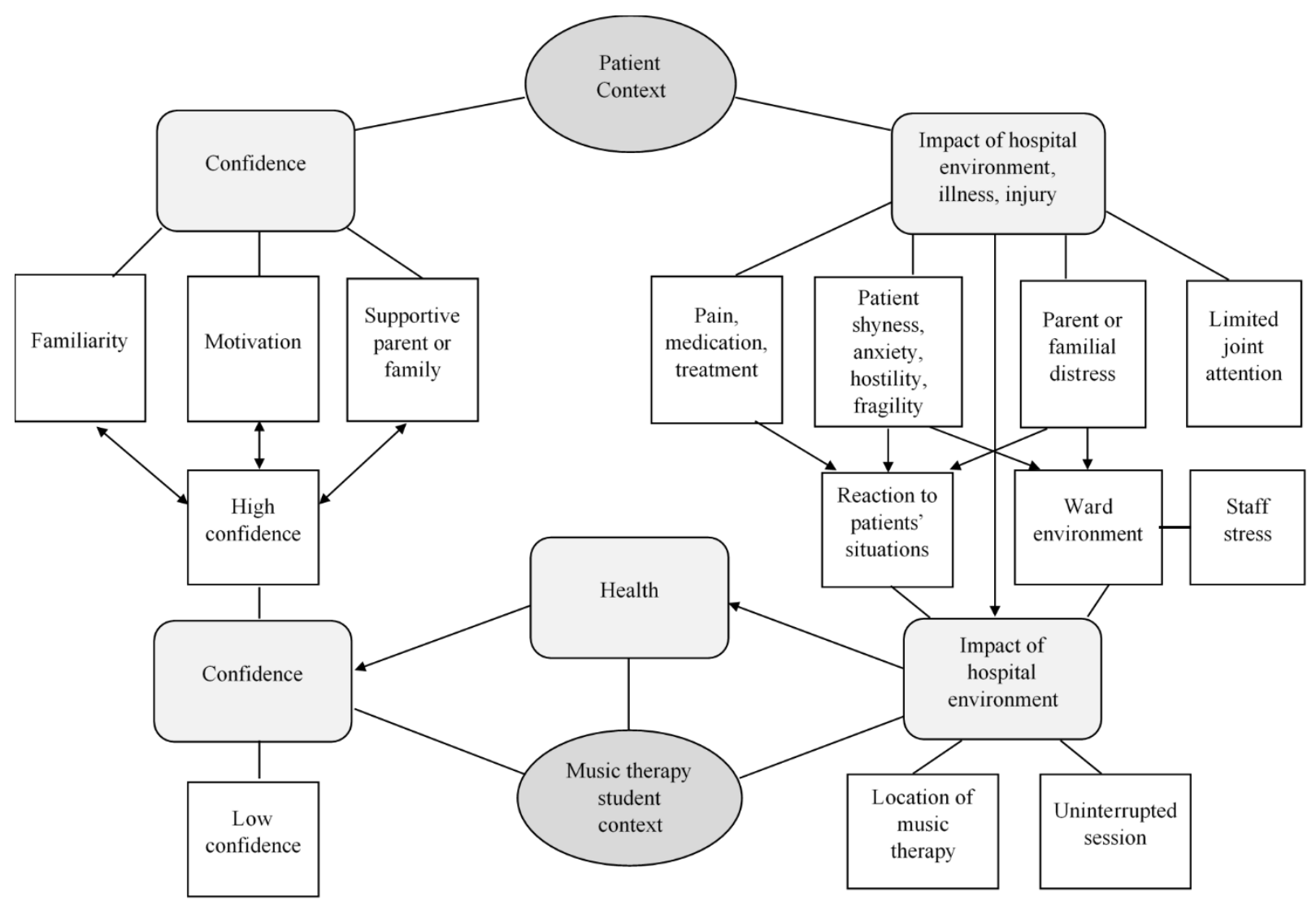

It is possible to categorise 'confidence' and 'impact of hospital environment' under a broader theme of psychological context. However, this may over simplifying things considering the interplay of physical, social and organisational ingredients.

Psychologically, for the patient, the sometimes foreign, often unpredictable hospital ward was not their chosen environment: they were there because of their illness or injury. They were away from home and outside the routine of their usual lives. They experienced pain, treatments, and dealt with multiple people; some were affected by personal trauma. Patients reacted in myriad ways to their situation. Likewise, parents, caregivers or other family members reacted to their child's illness or injury, the disruption to their usual lives, and the experience of the hospital system in myriad ways. The interplay between patients, families and ward staff is beyond the scope of this study, however, what was happening on the ward impacted staff (and vice versa) and therefore the overall atmosphere on the ward. In turn, I reacted to patients' conditions, situations, familial and staff responses. Playfulness was less evident in situations where pain, medication and patient or family 
distress were heightened. It was difficult - and not always appropriate - to maintain a playful attitude in this stressful environment.

Limited joint attention sometimes impacted on playfulness. My ability to be playful with a child was sometimes restricted when a child lived with a neurodevelopmental condition, like Autism Spectrum Disorder (ASD). In these cases, it was difficult to establish joint attention with them. This was especially true when the location for music therapy was the playroom; a shared space, full of stimuli and many toys that I could not moderate.

A busy playroom occupied by three children and their respective parents. Wiremu, 5, was flitting between drums and a toy xylophone. I tried but was unable to establish any ongoing music interaction with him. Likewise, I was unable to establish any music interaction, in fact any interaction, with Xavier, 13 months. Similarly, with Marlo, 9 who had ASD. Marlo was moving quickly between different toys and instruments in room and around the other children, engaging with various toys and equipment. I attempted to use music to draw them all in but it didn't work.

(Clinical music therapy notes, June 24.)

Sometimes lack of joint attention was due to a child's anxiety and hypervigilance where their stressed state meant their thought processes were very fast. It seemed their protective mechanisms prevented them from relating to other people. Sometimes drugs like Prednisone, a common medication in the treatment of severe asthma, caused hyperactivity in children and restricted their capacity for joint attention.

The physical and organisational aspects of the hospital environment impacted on playfulness in two ways. First, it was difficult to maintain connection, collaborate, be spontaneous, humorous and remain 'in the moment' when sessions were held in multipurpose spaces. Here medical consultations, examinations or procedures, the arrival of other patients or visitors took precedence. Playful moments occurred more frequently during uninterrupted music therapy. Second, the challenges caused by shared space and medical scheduling meant finding my place, as a student therapist, within the multidisciplinary team was not always easy: this affected my confidence, especially when I had been ill. 
Confidence increased when participant and therapist were familiar with each other i.e. during second or subsequent music therapy sessions or periods of general interaction. Motivated and enthusiastic children, parents or caregivers approached music therapy with greater confidence, which impacted on my confidence. This mutual confidence created greater potential for playfulness.

In summary, negative impacts on playfulness for patients included the presence of pain or state-affecting medication, children's stress reactions to their illness, injury or the hospital environment and familial distress. Playfulness was less likely when music therapy occurred in the treatment room or when sessions were interrupted. Music therapy student illness, low confidence and a stressful ward environment negatively impacted on playfulness during this specific period. Positive impacts on playfulness for children were confidence associated with motivation, presence of supportive family, and familiarity with the music therapy student. The absence of pain had an impact. For the music therapy student, positive impacts on playfulness were confidence and good health. Playfulness was more likely when music therapy took place in the playroom or at a patient's bedside and was uninterrupted. Features of playfulness which were most prominent in this stressful period were: proactive invitations; promoting children's role in play; accepting children's ways of playing instruments; providing opportunities for learning, risk taking and creativity; use of resources which promoted autonomy and choice. Building rapport and giving children time to warm up continued to be important. Humour, incongruence and joyous moments decreased. When playfulness was reduced, my previously extended tool kit of collaborative music therapy skills and approaches provided a structure that acted as a buffer, enabling me to continue in my work.

When it was difficult or seemingly inappropriate to maintain a playful attitude, or experience reciprocating playfulness in a dyad, I questioned how relevant the original construct of playfulness remained. Playfulness involving spontaneity, humour and incongruence seemed increasingly out of place when working with patients and families in very serious, sometimes traumatic, situations. When playfulness was reduced, was it acceptable to only transition a child into a state of play? Where did playfulness fit? Winnicott's writing $(2005$, p. 51) reassured me as he discussed the importance of play in therapy: 
"Psychotherapy has to do with two people playing together. The corollary of this is that where playing is not possible [because of the state of the patient] then the work done by the therapist is directed towards bringing the patient from a state of not being able to play into a state of being able to play”.

I propose that this applies to sick children in hospital, experiencing myriad psychological impacts of admission, illness or injury. Moving into play via music therapy seemed as far as some children could go considering their situation. Likewise Gordon (2014) upholds the importance of attuned play as a means to restoring playfulness and encourages the reader not to underestimate the value of keeping playful company as a step in this process. The literature bolstered my confidence in the music therapy-play process and in the value in promoting playfulness, even if that goal was not reached within limited music therapy sessions. When I was not feeling playful, being in music therapy with children where I was collaborative, attuned and interactions were intersubjective still had value (Alcock, 2016). 


\section{Discussion}

Incorporating playfulness into my practice was a multifaceted experience. The characteristics of playfulness I employed varied when working with children of different ages. My playfulness was impacted on by various personal and situational factors. Results from my first research cycle aligned with existing literature on playfulness where playfulness involved spontaneity, freedom from rules, incongruence, humour and joy (Akhtar et al., 2011; Lieberman, 1977; Tegano \& Moran, 2007). The cognitive, social and physical spontaneity described in playfulness literature was incorporated into the broader theme of being childlike. Being childlike included relating spontaneously but broadened to include the childlike qualities of imitation, exaggerated speech and being on the same physical level. Exaggeration was frequent with young children. Musical elements of improvisation (Bruscia, 1987) were also a significant subset of relating spontaneously. Akhtar's (2011) mutual playfulness was easy to attain in this cycle, especially with young children.

I next incorporated playfulness into my practice by developing a greater understanding of play and development in middle childhood and by better equipping myself for music therapy practice with this age group. Analysis of data showed that playfulness occurred when there was time to warm up, during collaboration and in humour. The most encompassing theme was collaboration, a key aspect of being childlike in middle childhood. Collaboration was an anticipated gateway to playful interactions with this age group. The breadth of data relating to collaboration illustrated my developing skills. It also coincided with the developmental drive in children for increased cognitive and physical skill development (Arnett, 2012; Fromberg \& Bergen, 2015), social complexity and cooperation (Zembar, 2009). Accepting a child as a unique person and not forcing their participation but working in response to their readiness to participate, seemed important in promoting playfulness. Freedom and choice, without an adult imposed agenda, brought music therapy into the realm of play (Howard et al., 2017).

The impact of confidence and the hospital environment on playfulness for myself and for patients was noticeable. Playfulness was enhanced when each person could attend to and read the cues of the other. The attunement, intersubjectivity and collaboration of playfulness which Alcock (2016) describes, occurred more often when I was healthy and confident and when patients were supported by family, their pain was managed and they 
were motivated. Familiarity between patient and music therapist was beneficial also. Regarding the environmental context, mutual attunement was aided when sessions were uninterrupted, and occurred in either the playroom or at bedside. Lack of playfulness occurred when patients were distressed or experiencing pain; when their families reacted negatively to the stress of the situation, when I was ill or lacking confidence. As playfulness is a characteristic of healthy development and wellbeing (Gordon, 2014; Winnicott, 2005) it is logical that entering into a state of playfulness is more difficult for any person whose development or health is compromised. This extends to children whose early relationships have been compromised, meaning they are not well practiced in playing or being playful (Youell, 2008). Play and playfulness also require a person to feel safe (Bateson, 2015; Gordon, 2014; Sayeed \& Guerin, 2000). Illness, injury, invasive treatments, loss of control and separation from family, common in a child's experience of hospital (Turry, 1999; Wolfe \& Waldon, 2009) affect a child's sense of safety and security. Creating an environment that enables a child to draw on music - songs or musical behaviours - as a transitional object is beneficial (Custodero et al., 2016). Therapy in a relaxed, playful therapeutic environment (with a relaxed, playful therapist) can facilitate a sense of safety and promote healing and growth (Gordon, 2014). C. Schaefer and Greenberg (1997) boldly suggested that playfulness in a play therapist makes them appealing to a child. Music therapy with a playful music therapist should therefore promote safety, healing and growth by fostering intersubjective, attuned play and playfulness. The relevance of the therapist's health and wellbeing as a mutual player must be considered.

Lack of playfulness was a relevant phenomenon in two ways. First, lack of playfulness was a clinically deliberate approach on my part, as it was not always appropriate to be overtly playful. Pain, uncertainty, distress and disruption were often significant and allencompassing for children and families. It was important to assess how people presented and then respond in a way that was most suitable. Reading the right moment to be playful, if any, was key. As Briggs (2015) states, when working within the developmental approach, matching a participant's affect and aiming for affect attunement, is an essential aspect of intersubjectivity: empathetically meeting a child or family member in their emotional state is necessary for the therapeutic process. Without intersubjectivity, playfulness is not possible (Alcock, 2016). Matching affect, therefore, whether playful or not, is arguably a first step in becoming playful. 
Second, examining the lack of playfulness in myself, while an uncomfortable process, was relevant to me as a reflexive practitioner. My lack of playfulness was significantly related to a period of ill health and the cumulative exposure to others' trauma and a stressful environment; an idea supported by Chang, Qian, and Yarnal (2013). This lack of playfulness could have been an early indicator of secondary traumatic stress, which Zeidnera, Hadara, Matthews, and Roberts (2013, p. 596) describe as the "stress resulting from knowledge about a traumatizing event experienced by another and from wanting to help the suffering person." This can be experienced by students in training (Butler, Carello, \& Maguin, 2017), new entrants to the health professions, especially those working with children (Meyer, Li, Klaristenfeld, \& Gold, 2015) and music therapists (Trondalen, 2016). Self-care practices can lessen the impact of secondary trauma (Butler et al., 2017; Meyer et al., 2015) and are a vital component of music therapist effectiveness (Trondalen, 2016).

Experiencing vulnerability in my role was not pleasant and investigating it was not easy. I was surprised that the action research process unravelled, revealed, challenged and grew me. Embracing risk and vulnerability, and following the path of growth and change is a desired outcome of action research (Schutz \& Hoffman, 2017; Stige \& Skewes McFerran, 2016). Through it, I have acquired a first-hand appreciation of the importance of self-care, better appreciate the need to monitor my own psychological health and place greater value on my physical and psychological health. I have a new awareness of the qualities of playfulness in myself which will hopefully increase my effectiveness as a co-player in therapy (Howard \& McInnes, 2013). The place of playfulness as an indicator of wellbeing (Winnicott, 2005) for the therapist is a valuable outcome of this research.

At the outset of this research, I anticipated exploring playfulness as a tool; an attitude I could employ to support my music therapy practice with children and facilitate optimal therapeutic experiences. I assumed that learning about playfulness would be about learning how to relate well to children and make music therapy appealing and fun in the hospital setting. While I did learn a lot about these things and enhanced my practice as a result, I learnt the value of playfulness in myself as an indicator of personal wellbeing. More importantly, I developed an appreciation of the prerequisites for playfulness and a greater confidence in my ability to assess patient and family needs and to engage in 
playfulness when appropriate. I believe this research process has helped me develop in the essential dual therapeutic roles of observant therapist and mutually engaged player (Hess \& Bundy, 2003; Trevarthen \& Panksepp, 2017).

\section{Limitations}

This research is based on my music therapy practice as a student on a paediatric ward. The findings are specific to my experience during this period and are not generalizable. This study was limited in size and scope by the parameters set by the university. For a study of this size and nature, data capture methods were suitable. While use of video as a data gathering method could have expanded my understanding of playfulness and how I exhibited a playful approach, this was not an appropriate method within the hospital context and with a vulnerable population. Playfulness was a difficult phenomenon to capture because of its nuanced and complex nature. Data collection and analysis were bound by my perspective but were moderated by my research supervisor. Again, this was appropriate to the scale of this research. This study did not investigate cultural differences in playfulness. Better understanding and representing playfulness attitudes and behaviours in the cultures of the various children I worked with, may have altered the results of this study. 


\section{Conclusion}

Employing an action research approach, I explored how I incorporated playfulness into my music therapy practice on a paediatric ward. This active research process required me to reflect on and develop my understanding of playfulness in my practice and its wider context. I discovered that playfulness was enhanced when I exhibited developmentally appropriate childlike behaviours, suitable for the age of child I worked with. Playfulness emerged differently with children in early childhood compared to middle childhood. The ability of either child or music therapy student to contribute to and reciprocate in playfulness was positively and negatively affected by psychological factors like confidence and reactions to personal situations, physical health, the physical environment, and organisational factors. Playfulness was shown to be a marker of health and wellbeing in the music therapy student. Experiencing a lack of playfulness was a potential indicator of secondary traumatic stress and the need for increased self-care for the music therapy student. Equally, exhibiting a lack of playfulness was an appropriate clinical strategy which enabled the music therapy student to match the affective state of a participant, thus supporting the intersubjective therapeutic process. This research raises the relevance of playfulness as a viable therapeutic marker in music therapy when working with children and adolescents in the paediatric setting. It also raises the relevance of playfulness as a viable indicator of music therapist health and wellbeing. 


\section{References}

Akhtar, M., Kieffer, C., Akhtar, S., Bergman, A., Bornstein, M., Brenner, I., . . Herzog, J. (2011). Play and playfulness: Developmental, cultural, and clinical aspects. Blue Ridge Summit, USA: Jason Aronson, Inc.

Alcock, S. J. (2016). Young children playing: Relational approaches to emotional learning in early childhood settings. Singapore: Springer.

Amir, D. (2005). Musical humour in improvisational music therapy. Australian Journal of Music Therapy, 16, 3.

Arnett, J. (2012). Human development: A cultural approach. Upper Saddle River, N.J: Pearson.

Ayson, C. (2007). Child-parent wellbeing in a paediatric ward: The role of music therapy in supporting children and their parents facing the challenge of hospitalisation. (Master of Music Therapy Dissertation), Victoria University of Wellington/Massey University, Wellington: New Zealand.

Bateson, P. (2013). Play, playfulness, creativity and innovation. Cambridge: Cambridge University Press.

Bateson, P. (2015). Playfulness and creativity. Curr Biol, 25(1), R12-16. doi:10.1016/j.cub.2014.09.009

Bateson, P. P. G. (2013). Play, playfulness, creativity and innovation. Cambridge: Cambridge University Press.

Bennett, P. (2016). Playfulness is an attitude: A practice that revitalizes teaching and learning. Retrieved from https://alfredledgerlines.wordpress.com/2016/06/15/playfulness-is-an-attitude-apractice-that-revitalizes-teaching-and-learning/

Berger, K. S. (2014). The developing person through the life span (9th ed.). New York, NY: Worth Publishers.

Bergold, J., \& Thomas, S. (2012 ). Participatory research methods: A methodological approach in motion. Forum: Qualitative Social Research, 13(1). doi:http://dx.doi.org/10.17169/fqs-13.1.1801

Bradt, J., Potvin, N., Kesslick, A., Shim, M., Radl, D., Schriver, E., . . KomarnickyKocher, L. T. (2015). The impact of music therapy versus music medicine on psychological outcomes and pain in cancer patients: A mixed methods study. Support Care Cancer, 23(5), 1261-1271. doi:10.1007/s00520-014-2478-7

Briggs, C. (2015). Developmental approaches. In B. L. Wheeler (Ed.), Music therapy handbook. New York, NY: The Guildford Press.

Brooks, M., \& O'Rourke, A. (2002). Opening doors: Music therapy in hospitals and hospices. Wellington, New Zealand: Wellington Society for Music Therapy. 
Bruscia, K. E. (1987). Improvisational models of music therapy. Springfield, Ill.: C.C. Thomas.

Bruscia, K. E. (2013). Defining music therapy. Barcelona: University Park.

Burgoon, J., \& Bacue, A. (2003). Nonverbal communication skills. In J. O. Greene, B. R. Burleson, \& J. Rojas Wiemann (Eds.), Handbook of communication and social interaction skills. Mahwah, USA: Routledge.

Butler, L. D., Carello, J., \& Maguin, E. (2017). Trauma, stress, and self-care in clinical training: Predictors of burnout, decline in health status, secondary traumatic stress symptoms, and compassion satisfaction. Psychological Trauma: Theory, Research, Practice, and Policy, 9(4), 416-424.

Chang, P.-J., Qian, X., \& Yarnal, C. (2013). Using playfulness to cope with psychological stress: Taking into account both positive and negative emotions. International Journal of Play, 2(3), 273-296. doi:10.1080/21594937.2013.855414

Costello, P. J. M. (2003). Action research. London: Bloomsbury Publishing PLC.

Custodero, L. A., Calì, C., \& Diaz-Donoso, A. (2016). Music as transitional object and practice: Children's spontaneous musical behaviors in the subway. Research Studies in Music Education, 38(1), 55-74. doi:10.1177/1321103X15612248

Drewery, W. (2004). Human development in Aotearoa: A journey through life (2nd ed.). Sydney: McGraw-Hill.

Duarte, A. (2017). Getting together, playing together, healing together. How to craft a somati-based activity. In S. Hart (Ed.), Inclusion, play and empathy: Neuroaffective development in children's groups. London and Philadelphia: Jessica Kingsley.

Edwards, J., \& Kennelly, J. (2011). Music therapy for children in hosptial care. In A. Meadows (Ed.), Development in music therapy practice: Case study perspectives. Gilsum, NH: Barcelona.

Edwards, J., \& Kennelly, J. (2016). Music therapy for hospitalized children. In J. Edwards (Ed.), Oxford handbook of music therapy. Publishded online: Oxford University Press.

Fagen, R. M. (2010). Play and development. In P. Nathan \& A. D. Pellegrini (Eds.), The Oxford handbook of the development of play: Oxford Handbooks Online.

Fromberg, D. P., \& Bergen, D. (2015). Play and socialization in middle childhood. In D. Bergen \& D. P. Fromberg (Eds.), Play from birth to twelve: Contexts, perspectives, and meanings (3rd ed.). New York: Routledge.

Gordon, G. (2014). Well played: The origins and future of playfulness. American Journal of Play, 6(2), 234.

Guitard, P., Ferland, F., \& Dutil, É. (2005). Toward a better understanding of playfulness in adults OTJR: Occupation, Participation and Health, 25(1). 
Haire, N., \& MacDonald, R. (2019). Humour in music therapy: A narrative literature review. Nordic Journal of Music Therapy, 1-18.

doi:10.1080/08098131.2019.1577288

Hannan, A. (2008). Effective clinical practice in music therapy: Medical music therapy for pediatrics in hospital settings. In C. Colwell \& D. Hanson-Abromeit (Eds.), Using music to support medical interventions. Silver Spring, MD: American Music Therapy Association.

Harrison, C., \& Robinson, C. (2017). Looking deeper: Play and the spiritual dimension. In S. Lynch, D. Pike, \& C. à Beckett (Eds.), Multidisciplinary perspectives on play from birth and beyond (pp. 61-78). Singapore: Springer.

Hart, S. (2017). Should school be a place for fun and games? In S. Hart (Ed.), Inclusion, play and empathy: Neuroaffective development in children's groups. London and Philadelphia: Jessica Kingsley Publishers.

Hayward, K., Raine, J., \& Hendry, C. (2019). Developing 'negotiation capital': Influence and imagination in three and four-year-old triadic collaborative play in nursery. European Early Childhood Education Research Journal, 27(1), 15-27. doi:10.1080/1350293X.2019.1539432

Hess, L., \& Bundy, A. (2003). The association between playfulness and coping in adolescents. Physical \& occupational therapy in pediatrics, 23(2), 5-17.

Horvat, J., \& O'Neill, N. (2008). 'Who is the therapy for?': Involving a parent or carer in their child's music therapy. In C. Flower \& A. Oldfield (Eds.), Music therapy with children and their families. London and Philadelphia: J. Kingsley Publishers.

Hospital Play Specialists Association of Aotearoa/New Zealand. (2019). Retrieved from http://www.hospitalplay.org.nz/online/welcome.csn

Howard, J., \& McInnes, K. (2013). The essence of play: A practice companion for professionals working with children and young people. Oxon, UK: Routledge.

Howard, J., Miles, G., Rees-Davies, L., \& Bertenshaw, E. (2017). Play in middle childhood: Everyday play behaviour and associated emotions. Children and Society, 31, 378-389.

Hubbuck, C. (2009). Play for sick children: Play specialists in hospitals and beyond. In ProQuest (Ed.).

doi:https://ebookcentral.proquest.com/lib/vuw/detail.action?docID=465802

Isenberg, C. (2015). Psychodynamic approaches. In B. L. Wheeler (Ed.), Music therapy handbook (pp. 133-147). New York, NY: The Guildford Press.

Jones, M. (2018). The necessity of play for children in health care. (The children's corner: Perspectives on supportive care). Pediatric Nursing, 44(6), 303.

Karakul, A., \& Bolisik, Z. B. (2018). The effect of music listened to during the recovery period after day surgery on the anxiety state and vital signs of children and adolescents. The Journal of Pediatric Research, 5(2), 82. doi:10.4274/ipr.24892 
Kemmis, S., McTaggart, R., \& Nixon, R. (2014). A new view of research: Research within practice traditions. In The action research planner: Doing critical participatory action research (pp. 67-83). Singapore: Springer.

Kingi, T. K. R., Durie, M., Elder, H., Tapsell, R., Lawrence, M., \& Bennett, S. (2018). Maea te toi ora: Māori health transformations. Wellington, Aotearoa New Zealand: Huia Publishers.

Lee, J. H. (2016). The effects of music on pain: A meta-analysis. Journal of Music Therapy, 53(4), 430. doi:10.1093/jmt/thw012

Lewin, K. (1948). Action research and minority problems. In G. W. Lewin (Ed.), Resolving social conflicts: Selected papers in group dynamics (pp. 201-216). New York, NY: Harper \& Brothers.

Lieberman, J. N. (1977). Playfulness: Its relationship to imagination and creativity. In ProQuest (Ed.). doi:https://ebookcentral.proquest.com/lib/VUW/detail.action?docID=1882875

Lorenzato, K. (2005). Filling a need while making some noise: A music therapist's guide to pediatrics. London and Philadelphia: Jessica Kingsley Publishers.

Marsh, K., \& Young, S. (2015). Musical play. In G. McPherson (Ed.), The child as musician: A handbook of musical development (2nd ed.). New York: Oxford University Press.

Meyer, R. M. L., Li, A., Klaristenfeld, J., \& Gold, J. I. (2015). Pediatric novice nurses: Examining compassion fatigue as a mediator between stress exposure and compassion satisfaction, burnout, and job satisfaction. Journal of Pediatric Nursing, 30(1), 174-183. doi:10.1016/j.pedn.2013.12.008

Neugebauer, C. (2013). Children in general inpatient care. In J. Bradt (Ed.), Guidelines for music therapy practice in pediatric care. Gilsum: NH: Barcelona Publishers.

O'Callaghan, C., Dun, B., Baron, A., \& Barry, P. (2013). Music's relevance for children with cancer: Music therapists' qualitative clinical data-mining research. Soc Work Health Care, 52(2-3), 125-143. doi:10.1080/00981389.2012.737904

Sayeed, Z., \& Guerin, E. (2000). Early years play: A happy medium for assessment and intervention. London: UK: David Fulton.

Schaefer, C., \& Greenberg, R. (1997). Measurement of playfulness: A neglected therapist variable. International Journal of Play Therapy, 6(2), 21-31.

Schaefer, C. E., \& Drewes, A. A. (Eds.). (2014). The therapeutic powers of play: 20 core agents of change (2nd ed.). Hoboken, NJ: John Wiley \& Sons, Inc.

Schutz, K. M., \& Hoffman, J. V. (2017). "I practice teaching": Transforming our professional identities as literacy teachers through action research. The Reading Teacher, 71(1), 7. doi:10.1002/trtr.1592 
Stegemann, T., Geretsegger, M., Phan Quoc, E., Riedl, H., \& Smetana, M. (2019). Music therapy and other music-based interventions in pediatric health care: An overview. Medicines, 6(1), 25.

Stige, B., \& Skewes McFerran, K. (2016). Action Research. In B. L. Wheeler \& K. M. Murphy (Eds.), Music therapy research (Third ed.). Dallas, TX: Barcelona Publishers.

Sundar, S., Ramesh, B., Dixit, P. B., Venkatesh, S., Das, P., \& Gunasekaran, D. (2016). Live music therapy as an active focus of attention for pain and behavioral symptoms of distress during pediatric immunization. Clinical Pediatrics, 55(8), 745-748. doi:10.1177/0009922815610613

Tegano, D., \& Moran, J. (2007). Play and creativity: The role of the intersubjective adult. In D. Sluss \& O. Jarrett (Eds.), Investigating play in the 21st century (Vol. 7). Maryland, USA: University Press of America.

Trevarthen, C., \& Panksepp, J. (2017). In tune with feeling: Musial play with emotions of creativity, inspiring neuroaffective development and self-confidence for learning in company. In S. Hart (Ed.), Inclusion, play and empathy: Neuroaffective development in children's groups. London and Philadelphia: Jessica Kingsley Publishers.

Trondalen, G. (2016). Self-care in music therapy: The art of balancing. In J. Edwards (Ed.), The Oxford handbook of music therapy. Oxford Handbooks Online: Oxford University Press. doi:10.1093/oxfordhb/9780199639755.013.49

Tucquet, B., \& Leung, M. (2014). Music therapy services in pediatric oncology: A national clinical practice review. Journal of Pediatric Oncology Nursing, 31(6), 327-338. doi:10.1177/1043454214533424

Turry, A. (1999). A song of life: Improvised songs with children with cancer and serious blood disorders. In J. De Backer \& T. Wigram (Eds.), Clinical applications of music therapy in developmental disability, paediatrics, and neurology. London, Philadelphia: Jessica Kingsley.

van der Heijden, M. J., Oliai Araghi, S., van Dijk, M., Jeekel, J., \& Hunink, M. G. (2015). The effects of perioperative music interventions in pediatric surgery: A systematic review and meta-analysis of randomized controlled trials. PLoS One, 10(8). doi:10.1371/journal.pone.0133608

Wheeler, B. L., \& Bruscia, K. (2016). Overview of music therapy research. In B. L. Wheeler \& K. M. Murphy (Eds.), Music therapy research (3rd ed.). Dallas, TX: Barcelona Publishers.

Wigram, T. (2004). Improvisation: Methods and techniques for music therapy clinicians, educators, and students. London, United Kingdom: Jessica Kingsley Publishers.

Williams, M., \& Moser, T. (2019). The Art of Coding and Thematic Exploration in Qualitative Research. International Management Review, 15(1), 45-72.

Winnicott, D. W. (2005). Playing and reality. London, UK: Taylor \& Francis Group. 
Wolfe, D. E., \& Waldon, E. G. (2009). Music therapy and pediatric medicine: American Music Therapy Association.

Yates, G. J., Beckmann, N. B., Voss, M. E., Anderson, M. R., \& Silverman, M. J. (2018). Caregiver perceptions of music therapy for children hospitalized for a blood and marrow transplant: An interpretivist investigation. Global Advances in Health and Medicine, 7. doi:10.1177/2164956118788853

Yates, G. J., \& Silverman, M. J. (2015). Immediate effects of single-session music therapy on affective state in patients on a post-surgical oncology unit: A randomized effectiveness study. The Arts in Psychotherapy, 44, 57-61. doi:10.1016/j.aip.2014.11.002

Yinger, O. (2016). Music therapy as procedural support for young children undergoing immunizations: A randomized controlled study. Journal of Music Therapy, 53(4), 336-363. doi:10.1093/jmt/thw010

Youell, B. (2008). The importance of play and playfulness. European Journal of Psychotherapy \& Counselling, 10(2), 121-129. doi:10.1080/13642530802076193

Zeidnera, M., Hadara, D., Matthews, G., \& Roberts, R. (2013). Personal factors related to compassion fatigue in health professionals. Anxiety, Stress, \& Coping, 26(6), 595609.

Zembar, M. J. (2009). Middle childhood development: A contextual approach. Upper Saddle River, N.J: Merrill/Pearson. 


\section{Appendices}

Appendix 1. Facility Consent Request

\section{CONSENT FOR MUSIC THERAPY RESEARCH}

Thank you for providing me with a clinical placement opportunity on the Children's Ward while I complete my Master of Music Therapy programme at the New Zealand School of Music, Victoria University of Wellington.

Along with my practical music therapy work, I am required to undertake a research study relating to my practice. I am writing to ask you, on behalf of the facility, to give me consent to carry out this research.

I am interested in the intersection between therapeutic play and music therapy.

Consequently, I am planning to investigate playfulness in music therapy in this setting, through an action research process. I will not be carrying out research on any patients, visitors or staff. My music therapy practice will be the focus of the research. My practices, behaviours, skills, reactions, reflections and decision making will be the content of the research data, analysis and reporting. As I document my research, I will protect the anonymity and confidentiality of the people I work with and not include any information that may identify them, the hospital or hospital staff. The Victoria Human Ethics Committee has given generic approval to Master of Music Therapy Programme for student research, undertaken as observational studies, theoretical or case study research or action research (ref: \#22131, 2015).

I hope you can grant me consent to complete this aspect of my placement. I am more than happy to answer any questions you may have about this work. Alternatively, you can contact my research supervisor at the university, , Senior Lecturer (Music Therapy), New Zealand School of Music, ph:

Thanks for your consideration

Rachel Austin

Consent granted/declined

Date: Name:

Signed: 
Appendix 2. Vignette Consent Request

\title{
MUSIC THERAPY PROGRAMME (MMUSTher)
}

\author{
Case Vignette - Information and Consent Form
}

Hello. I am Rachel Austin, the music therapy student currently working at.

who worked with during their admission in

As part of the requirements for my music therapy clinical placement I am required to complete an exegesis, illustrated by a vignette from my clinical work. I am writing to ask if I can describe the work I have done with in my exegesis.

The exegesis including the case vignette will be sent for examination. The examiners will be both internal and external to the New Zealand School of Music, Victoria University of Wellington. The exegesis will also be published in the Victoria University of Wellington library, in hard copy and as an online resource.

If you agree, the case vignette is likely to include background information about Anonymity will be protected whenever possible, with all information that

might identify and/or the name of the facility being removed. I will use a pseudonym when describing material in my case vignette.

Please take time to think about this and ask any questions you might have. When you are sure you agree that I can write about in my case vignette, please sign both copies of this letter, keep one, and give one back to me. If you would like a copy of the case vignette and/or exegesis, it will be provided for you after the work has been completed and examined, following the conclusion of my placement.

I give consent for information about to be included in the case vignette described above.

Name Signature Date.

Parent/guardian or representative

Name Signature Date. Facility representative

This consent expires on 31 January 2020 and may be withdrawn at any time by contacting the Music Therapy Programme Director at 


\section{Appendix 3. Coding Example}

B2F. Abdominal pain. Multiday stay. I noticed B2F walking towards the playroom. She had not often come into the playroom, had previously been coy and seemed timid in the space, although was gradually become more adventurous and had been starting to come in. I had the ukulele and started to sing (to the tune of Oma Rapeti) 'Hello B2F, hello B2F, won't you come on in?' She smiled and came into the playroom. She went directly to the keyboard and pushed the button so it played preprogrammed music. She was just starting to listen to this when the nurse came and said it was time for her medicine. She and her caregiver headed back to the room with the nurse. As she went, I heard the nurse say that she didn't like getting her medicine (via n/g tube). I decided I could offer some support for this procedure and went to her room with my ukulele and a drum. I offered her the drum - she had sock bandages on her hands to stop her taking out her nasal gastric tube. With encouragement she started to hit the drum with her hands. I improvised songs as she played.

While this happened, the nurse wa medicine. Her caregiver held the drum for her. We kept playing with the drum. I sang an invitation to play, including playing the drum with her feet, then with her knee, with her elbow, with her head, with her other foot. Her helper moved the drum and held it in the relevant places for her. We played starting and stopping games, playing up, down, over to one side then over to the other. I made my voice match the direction. I had been making up lyrics for a while so decided to continue with the silliness of the game and vocalised scat 'bibbidy, bibbidy ba, diditty, diditty, diditty diditty da...' I started each phrase

with an exaggerated inhalation, raised torso and eyebrows; I wiggled my head as a vocalised. I left space and just played ukulele in between phrases so she could drum, which she did. I matched the rhythm of my ukulele playing with the rhythm of my scat. She beat the drum energetically, rapidly, with two hands, using big movements. Her feet moved with her hands, swinging back and forth. She was animated and engaged in the music and the game. The nurse had then finished giving her the medicine. We continued playing for a short time after the nurse had finished. I turned the ukulele over and used it as a drum, drumming the back of it. She looked at me and shook her head. I said, "This way?" I turned it on its head, held it between my knees and played the base of it like a drum. She shook her head but smiled. Again, "This way?" I turned it so I played the tip of the neck. She shook her head, involved in the game. She motioned for me to turn it over. "This way?" I drummed on the strings. She shook her head._I started to strum; she continued to drum. She was then collected for her next appointment.
I am joyful

Use of sung speech rather than spoken

Invention and improvisation

Unusual way of playing

instrument

$\underline{I}$ am free from rules

Anticipation - instruments

Music elements reflect actions

I am joyful

Physical spontaneity

Music elements reflect my actions

I am free from rules

Unusual way of playing

instrument

I use humour 


\section{Appendix 4. Action Research Process}

How is playfulness incorporated in music therapy practice in a paediatric setting?

\section{The Action Research Process}

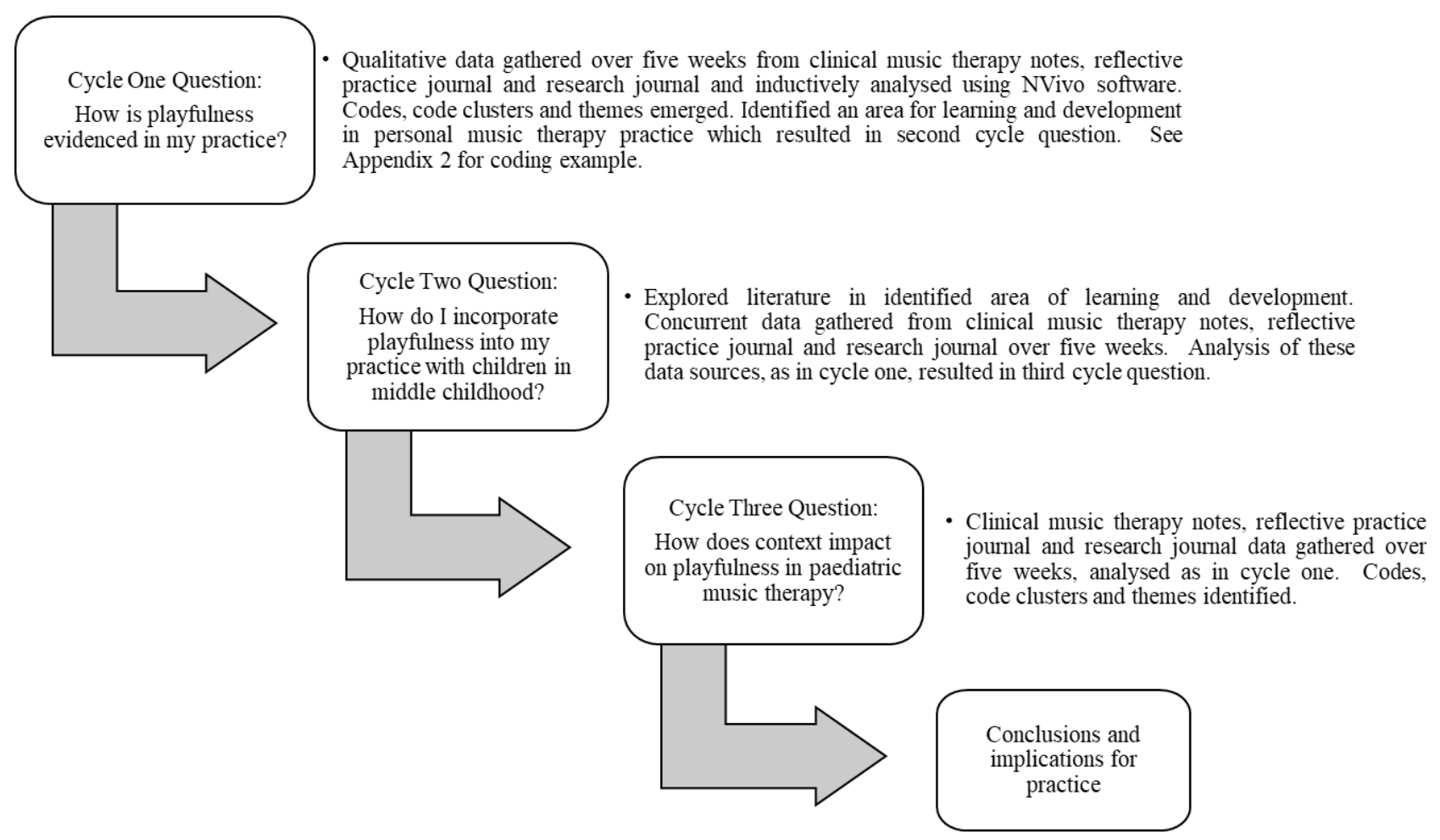

